University of Louisville

ThinkIR: The University of Louisville's Institutional Repository

$5-2012$

\title{
Investigating commenting formats and content in first year composition and the virtual writing center.
}

\author{
Rebecca Hallman \\ University of Louisville
}

Follow this and additional works at: https://ir.library.louisville.edu/etd

\section{Recommended Citation}

Hallman, Rebecca, "Investigating commenting formats and content in first year composition and the virtual writing center." (2012). Electronic Theses and Dissertations. Paper 563.

https://doi.org/10.18297/etd/563

This Master's Thesis is brought to you for free and open access by ThinkIR: The University of Louisville's Institutional Repository. It has been accepted for inclusion in Electronic Theses and Dissertations by an authorized administrator of ThinkIR: The University of Louisville's Institutional Repository. This title appears here courtesy of the author, who has retained all other copyrights. For more information, please contact thinkir@louisville.edu. 


\title{
INVESTIGATING COMMENTING FORMATS AND CONTENT IN FIRST YEAR COMPOSITION AND THE VIRTUAL WRITING CENTER
}

\author{
by \\ Rebecca Hallman \\ B. A., Transylvania University, 2009

\begin{abstract}
A Thesis
Submitted to the Faculty of the

College of Arts and Sciences of the University of Louisville in Partial Fulfillment of the Requirements

for the Degree of
\end{abstract}

Master of Arts

Department of English

University of Louisville

Louisville, Kentucky

May 2012 


\section{INVESTIGATING COMMENTING FORMATS AND CONTENT IN FIRST YEAR}

COMPOSITION AND THE VIRTUAL WRITING CENTER

by

Rebecca Hallman

B.A., Transylvania University, 2009

A Thesis approved on

April 25, 2012

by the following Thesis Committee:

Dr. Joanna Wolfe

(Thesis Director)

Dr. Elizabeth Patton

Dr. Bronwyn Williams 


\section{ACKNOWLEDGEMENTS}

I would like to thank my professor, Dr. Joanna Wolfe, for her guidance and patience. I would also like to thank the other committee members, Dr. Bronwyn Williams and Dr. Elizabeth Patton, for their comments and assistance. 


\section{ABSTRACT \\ INVESTIGATING COMMENTING FORMATS AND CONTENT IN FIRST YEAR COMPOSITION AND THE VIRTUAL WRITING CENTER

\author{
Rebecca L. Hallman
}

May 12, 2012

Current scholarship indicates an increase in the use of asynchronous electronic formats by writing instructors and tutors responding to student writing. However, little research has been done to understand the ways in which different formats affect the content of teacher written response and students' perceptions of these responses and formats. This thesis presents the results from two studies: one in the first year composition classroom and the other in the virtual writing center. Both studies consisted of the collection, coding, and analysis of instructor and tutor responses to student writing in two formats: the in-text (marginal) commenting response and the end comment response. Two instructors, five virtual writing center tutors, and 6 students from two first year composition classroom were interviewed about their perceptions of these formats and forty-one composition students participated in a survey. Overall, instructors, tutors, and students preferred the in-text commenting format to the end commenting format. The response coding found that in-text commenting responses included shorter but more frequent comments compared to the end comment responses. In-text responses also included more question comments, teacher rewriting of student texts, sentence-level comments, and explanatory praise, while end comments provided a higher number of full-text and observatory comments. These studies point to the need for further 
exploration into the ways in which explanatory praise facilitates student revision as well as deeper investigation into questions about the roles instructors, tutors, and students play in student revision. 


\section{TABLE OF CONTENTS}

\section{PAGE}

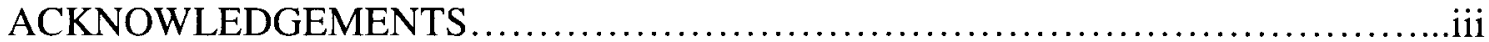

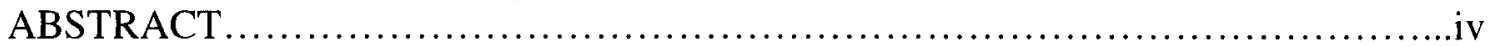

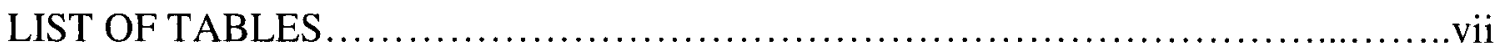

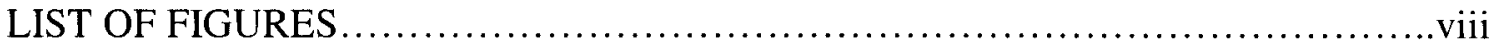

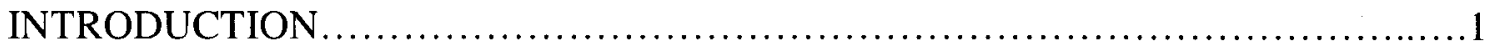

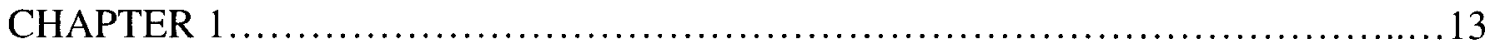

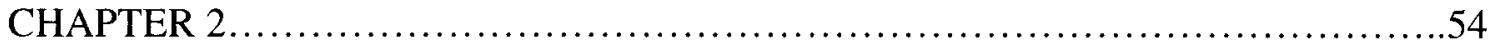

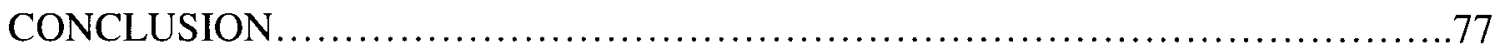

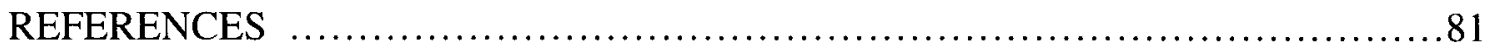

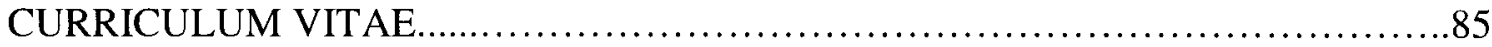




\section{LIST OF TABLES}

TABLE PAGE

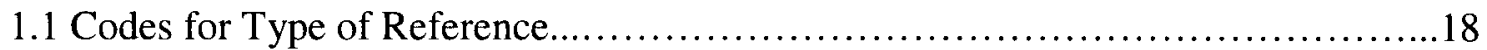

1.2 Codes for Degrees of Directiveness................................................ 19

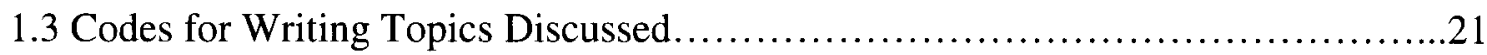

1.4 Characteristics of End Comment and In-text Comment............................23

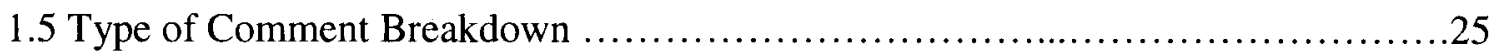

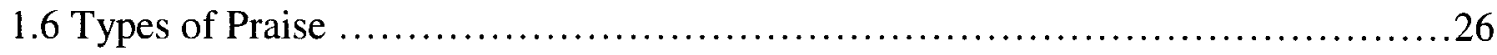

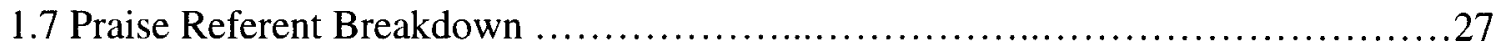

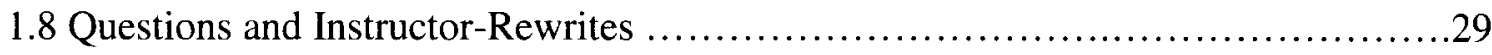

1.9 Instructor Rewrites at Full-text, Paragraph, and Sentence-level......................31

1.10 Number of Rules and Descriptions........................................ 32

1.11 Students' Average Perception of Format Preference and Confusion..............35

1.12 Students' Average Perception of Formats and Revision...........................36

1.13 Students' Average Perception of Formats and Writing Topics.....................37

2.1 Characteristics of VWC End Comment and In-text Comment......................58

2.2 Type of Comment Breakdown.................................................60

2.3 Overall Explanatory Comments by Referent.......................................60

2.4 Questions and Tutor Rewrites..............................................64

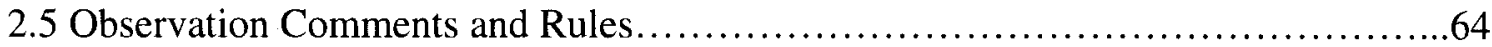

2.6 Erica's Comments as Instructor vs. Tutor.......................................66 


\section{LIST OF FIGURES}

FIGURE

PAGE

1.1 Sample Instructor 1 End Comment..............................................

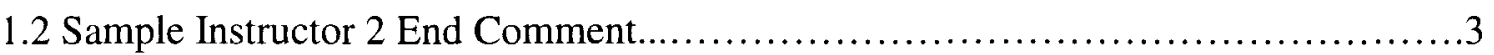

1.3 Sample Instructor 2 In-text Comment.......................................4

1.4 End Comment Broken into Referents............................................. 18

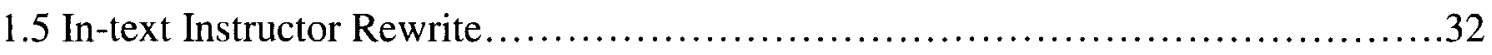

1.6 Praise Comment Identified by Julie as Helpful...................................39

1.7 Erica's End Comment with Praise Highlighted...................................40

1.8 Casey's End Comment................................................... 41

1.9 Lisa's End Comment....................................................43

1.10 Lisa's In-text Comment..............................................45

1.11 Molly's End Comment................................................46

2.1 Sample VWC End Comment.............................................59

2.2 Sample VWC In-text Comment..............................................59

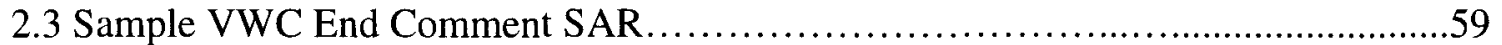

2.4 Alice's Minimal In-text Marking...........................................63 


\section{INTRODUCTION}

The act of commenting on student texts has concerned teachers for much of our discipline's history. The major concerns over how composition instructors create their comments and how students perceive those comments were first established in Sommers' seminal 1982 article "Responding to Student Writing," and Brannon and Knoblauch (1982). In the latter article, these scholars analyzed previous research on teacher commentary and expressed a concern over the lack of empirical evidence that shows how students respond to instructor comments. On the other hand, Sommers reported her findings from a study on teacher responses to student texts in which she concluded that instructor comments were often too general (vague and abstract commentary without text-specific directives), contradictory (asking students to condense and then later to expand), and without a clear prioritizing scheme for students to use during revision. Most importantly, Sommers concluded that "Written comments need to be viewed not as an end in themselves...but rather as a means for helping students to become more effective writers" (155). Following Sommers' lead, many scholars (Hayes \& Daiker, 1984; Ziv, 1984; Daiker 1989; Heller 1989) pursued research that sought to determine the ways instructors respond to student texts. One such project was Connors \& Lunsford's (1988) national study of teacher-marked student essays, in which they found that teachers tended to focus their comments on marking error. These markings were analyzed for patterns and used to determine a top ten list of errors in student writing. 
More recently, Lunsford \& Lunsford (2008) conducted a study which sought to replicate the 1988 study and also to compare current trends in teacher commentary and student errors with those of the past. While Lunsford \& Lunsford's research led to significant findings indicating changes in paper length, genre variety, and error patterns, one of the most striking discoveries was the lack of change in teacher comments over time. These researchers found that the majority of teachers continued to focus on a small number of error patterns and to construct handwritten responses to student texts. Even more surprisingly, within this data "only 56 of the 877 papers had comments that were made via technologies beyond the typed final comment; most typically, they employed Microsoft Words commenting or highlighting features" (794). Lunsford\& Lunsford attributed this infrequent use of electronic commenting tools to either a lack in accessibility and convenience or pedagogical discomfort.

Given that the majority of electronic responses to student writing use basic Microsoft Word features, this thesis project seeks to examine the ways in which two electronic commenting formats affect teacher response to student text in terms of frequency of comments, content, depth, and praise. The two formats investigated were the end comment, a longer, isolated, letter like response to student text which includes little to no minimal marking on student text (shown in Figures 1.1 and 1.2). And the intext comment, which consisted primarily of marginal textbox comments, highlighting, and track changes which appear directly on student texts (shown in Figure 1.3). 
Figure 1.1: Sample Instructor 1 End Comment

I enjoyed reading your narrative claim. It starts out strong with a clear thesis statement. Another strong aspect of it is the second half of the third paragraph (on page 2). You get into a lot of explicit details about what goes in to running a business. Here are a few suggestions I have to improve this essay upon revision:

1. Condense the second paragraph, and use it as the introduction for your thesis. It doesn't really make an explicit claim about an aspect of the career, but it seems like useful background information for your audience.

2. Reorganize and focus the third paragraph. I see the most clear points and examples in that second half. Can you pick out those and shape two solid paragraphs around them? One might be the "general" business information you learned, with a clear example added and the other paragraph would explain what you learned about operating a small business.

\section{Figure 1.2: Sample Instructor 2 End Comment}

Your writing is clear, and you made some very interesting points in your report. You describe how less time needs to be spent writing if the physician has seen the patient before, and you do a nice job of describing some of the writing preparation for a career in medicine. You also introduce sources well by including names and credentials and cite them correctly, so that rea ders know which source is "talking" in yourreport.

Another interesting point you presented was Dr. Miksanek's idea that medical writing is more public. I would agree with you that this statement sounds strange because when we think of writing by physicians, we think of privacy and doctorpatient confidentiality, so I would like to hear more about this idea of medical writing as public. Why does he argue that medical writing is public? Why does this notion sound so strange to us? Does he suggest that all medical writing is public, or is he talking more specifically about publishable writing (e.g., research findings)?

You could also say more about the specific kinds of writing that physicians do, and remember to separate the writing they do from the reading that they do. In the first paragraph, you write, "Doctors put their writing skills into action by interpreting charts," but I'm not sure if "interpreting" is a way of writing. This sounds more like the rea ding that doctors do. You might also say more about the "e-mails from fellow physicians or filling out forms to admit a patient to the hospital" that Dr. Schumann mentioned (page 2). What more can you say about these types of writing?

Finally, you quote Dr. Schumann as saying that people in the medical field need to have "strong writing skills" (page 1). What more can you say about this? Different fields and different genres requires different writing skills, so someone good at joumalistic writing might not be good at lab reports. What specific skills or knowledge does a personneed to have "strong writing skills" in medicine?

Overall, nice work. 


\section{Figure 1.3: Sample Instructor Two In-text Comment}

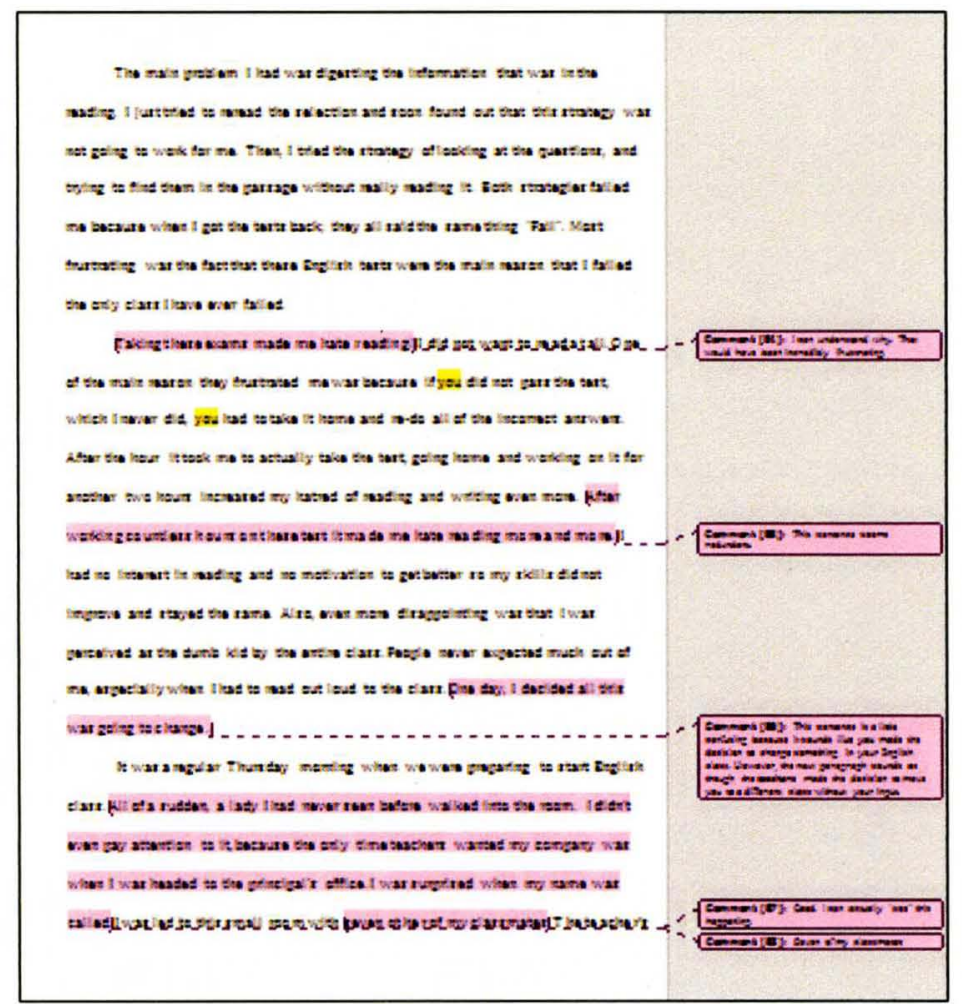

\section{Two Contexts: The First Year Composition Classroom and The Virtual Writing}

\section{Center}

These electronic response formats were collected from two contexts: the first year composition classroom and the virtual writing center (VWC). The first year composition classroom offered a quality location for the exploration of commenting formats because multiple responses in the same genre written by the same instructor were easily collected. This cite also made it possible to ensure that the same instructor commented on each students' writing in both formats. In addition, student response to instructor commentary was more convenient to obtain in the composition classroom because surveys could be administered and collected during class time. 
Additionally, responses to student writing in both formats written by tutors in the VWC were collected. One advantage to collecting responses in this context was that tutors were able to provide lengthy, in-depth responses to student writing because they were required to spend approximately 45 minutes on each session, which was most likely more time than the instructors were able to spend on their responses. One drawback to this venue was the regularity with which students used the VWC was not within this study's control, so only a few students received virtual responses in both of the two commenting formats and hardly any students received responses in both formats from the same tutor. However, this context was valuable because it allowed for a sample with more variety in terms of writing genres and student ability/grade level.

Conducting nearly the same study in these two writing contexts also provided the opportunity for examination of the ways in which teacher responses differed from and paralleled tutor responses.

\section{A Higher Preference for the End Comment}

Although much of the research on teacher commenting acknowledges both end comment and in-text commentary, many scholars seem to prefer the end comment to the in-text format. This preference is evident in Bean (2011) when he prefaces his argument with a reference to frustrated student reactions to "specific marginal comments" (240), and then claims that the instructor's job is to "coach revision" (242) through creating a hierarchy of higher and then lower order concerns. Bean's support for the end comment is especially clear when he provides particular suggestions for constructing an end comment whose purpose is "not to justify the grade but to help writers make the kinds of revisions that will move the draft toward excellence" (250). This tendency to favor the 
end comment over the in-text comment is not surprising considering earlier scholarship, such as that of Heller (1989), who strongly opposed the in-text comment. While Heller does acknowledge her own previous participation in the construction of marginal comments, she also claims that marginal comments are too directive because they silence student writers and undercut students' control over texts. She insists that instructor commentary should appear on a separate sheet of paper and that "no written marks or comments be made directly on the student's text" (italics are Heller's, 212). Heller's valuing of student autonomy over their own texts is admirable, yet her absolute rejection of the in-text comment seems problematic and harsh.

The end commenting format does indeed seem to follow a less directive approach because it provides students with suggestions for improvements without the tutor physically making changes to the student's actual text (as programs like Track Changes allow). In addition, the end comment is useful because it allows the tutor to prioritize high order concerns and encourages a kind of "strengths-major problemsrecommendations" formula (Bean, 2011), which makes it easier for tutors to maintain awareness of the number and kinds of comments they provide.

Yet, the end comment also has some potential drawbacks. One such drawback was acknowledged by Smith (1997), who analyzed over 200 end comments and found that most instructors developed "a pattern or response" (250) which ultimately became constraining. Smith explained that "when generic conventions become so strong that they lead teachers to make insincere statements, teachers' credibility and the effectiveness of the end comment may suffer" (254). The most common genre Smith found was a "judging genre" (252) which consisted primarily of evaluative comments. 
In addition, the end comment often lacks attention to local concerns (Beans 2011), which may be important for helping students to understand tone and develop their writing style. The end comment also usually addresses concerns in student writing out of context (so that students have to flip back through their essays and try to determine which parts of the paper comments are addressing). Since these comments are not anchored to student text, they may be more likely to promote the kinds of feedback Sommers (1982) cautions against: taking students' attention away from their own purposes in writing a particular text and instead focusing that attention on the tutor's comments. Although the end comment may be praised for seeming "less directive" and more minimalist, instructors and tutors might unintentionally construe their own ideas about what the students' text should /is doing, rather than maintaining close proximity to the actual words students have written. For this reason, I hypothesized that end commenting may provide a similar, or perhaps an even higher, degree of directive feedback when compared to that offered by in-text comments.

\section{Potential for the Effectiveness of In-text Comments}

Although in-text comments have not received much support in composition, some human factors in computing systems research findings suggest that in-text commentary may be more effective than we have assumed. Wojahn, Neuwirth \& Bullock (1998) conducted a study, in which they considered three different types of interfaces used to annotate texts: the end comment (what they call "split-screen") and in-text comments/ track changes (what they call "interlinear" and "aligned"). These researchers found that those who communicated using the in-text format commented more frequently than those who used end commenting. Yet, they found no significant difference in amount of high 
order concerns (what they call "high equivocal problems") reported. Instead, the in-text format produced a significantly greater number of low order concerns (what they call "low equivocal problems") than the end comment.

These findings from Wojahn et al. suggest that in-text responses could produce more overall feedback than the end comment, specifically on lower-order concerns, without reducing the number of comments focused on higher order concerns. However, what this study does not address is the quality of higher order concerns in each condition. One potential drawback to this kind of in-text commenting is the spatial constraint, which may result in comments that are somewhat vague, focus too much on grammatical concerns, and fail to provide reasons why the tutor/instructor makes a particular comment (Sommers, 1982; Bean 2011). If instructors/tutors provide reasons for commenting in particular ways, resist the temptation to be overly directive, and figure out how to prioritize comments, then in-text commenting formats could be the most effective strategy for instructors, tutors and students. Furthermore, some instructors/tutors may already be using such strategies effectively. This study aims at uncovering some of the processes used by instructors and tutors when they construct in-text and end commenting, in addition to determining the ways in which electronic format impacts the content of their comments.

Most past and recent scholarship on instructor response to student texts investigated comments in either the in-text form or the end comment (Heller, 1989; Smith, 1997), or focused on the content of responses without paying much attention to the ways in which the format and/or placement of those comments affected the content (Gee, 1972; Straub, 1996; Cho, Schunn \& Charney, 2006; McGarth, Taylor, \& Pychyl, 
2011). Even less work has been done to compare the different kinds of asynchronous electronic response formats available to instructors and tutors, yet some composition pedagogy and the majority of online writing centers encourage a non-directive approach to working with student writers. Thus, this thesis will attempt to determine the ways in which end comment and in-text commenting formats vary in degrees of directiveness.

\section{Lack of Research on Student Response to Instructor/Tutor Commentary}

One key insight into the effectiveness of these commenting formats can be provided only by student writers themselves. As Walker (2009) clearly indicates, in order for comments to be "usable" by students, they must "do more than simply point out a gap [between the meaning the student intends and the meaning the instructor comprehends]; [comments] must be designed to help the student to reduce or close the gap" (3). The need for research to determine the views students and teachers share and diverge was acknowledged by Straub (1997), who surveyed 142 first year college students about their perceptions of isolated, individual comments on a writing sample. Straub found that students could distinguish between different types of comments, were equally interested in receiving comments on global and local matters, appreciated when instructors recognized their ideas and became engaged with their subjects in their written responses, preferred specific and elaborate comments, determined their preferences for different comments according to the ways those comments were presented, responded favorably to praise and question comments, and disliked comments that asserted too much control over the student text. While these findings do offer valuable insight into the kinds of comments students prefer, they are also limited because they were gathered from isolated comments on a sample essay not written by the students themselves. 
Some research has been done to determine the ways in which students understand instructor responses to their own writing (Bardine 1999; Cho, Schunn, \& Charney, 2006) and the ways in which those responses foster or hinder revision (Dohrer, 1991; Walker, 2009; Phillips \& Wolcott, 2011). Like Straub, Bardine found that high school sophomore students particularly favored comments that were thoroughly explained and also appreciated praise. The students Bardine interviewed also expressed a desire for praise to be better explained so that it could then be used as a "model for future writing" (245).

With a focus on examining how comments affected student revision, in addition to student preference, Dohrer conducted student interviews and think-aloud protocols as they revised their own writing in between drafts. He found that students' revision strategies consisted primarily of addressing instructor comments with few additional revisions to other parts of their texts. Most interestingly, Dohrer's study revealed that students prioritized instructor comments according to the kinds of comments that appeared most frequently. He found that because instructors focused most of their comments on sentence-level concerns, students spent the majority of their time revising local errors. Since few instructor comments focused on global concerns compared to sentence level concerns, students more often overlooked these global comments. Perhaps most disturbingly, Dohrer noted that students "purged content to maintain the correctness they felt [was] most important to their teachers" (51). Thus, the students in Dohrer's study used the frequency of instructor comments to prioritize their own revision processes and also to construct their own ideas about the kinds of writing concerns instructors valued most. 
Yet ultimately, we have little knowledge of what kinds of commenting formats students prefer and which formats lead to the most successful revisions. While it is quite likely that students prefer in-text commenting because it often suggests small and easy sentence-level fixes (Bardine 1999), students may also find this format helpful when and if instructors/tutors address higher order concerns. Thus, this thesis project will attempt to understand students' perceptions of comments written in response to their own writing in different formats and also examine the ways students perceive their use of those comments in the revision processes.

\section{Research Questions}

The research questions explored in these two studies include:

1. What types of writing issues are addressed through in-text comments and not through end comments, and vice versa? What are the similarities in content between these two styles?

2. Is in-text commenting truly more directive than end commenting?

3. How do in-text comments address global issues (including purpose and audience) in addition to prioritizing concerns?

4. Is the quality of higher order concern comments better in end comment or in-text format?

5. How do students read in-text comments differently from end comments and what changes do students plan to make after reading comments in each format?

6. What strategies do instructors/ tutors use to overcome the limitations of either the in-text or the end comment format?

7. How do instructor/tutors' perceptions of their own comments align with and 
diverge from students' perceptions?

8. How does the content in instructor responses (in the first year composition classroom) differ from tutor responses (in the virtual writing center)? How are their processes for responding to student writing using each format similar and/or different?

What follows in this thesis is a first study in Chapter 1 which takes place in the first year composition classroom and includes a detailed discussion of the methods employed to answer these questions, the results of the analyses of instructor responses to student writing, student and instructor interviews and student surveys, and a discussion of the implications of these results for instructor practices and future research. A second study in Chapter 2 takes place in the virtual writing center and uses the same methodology outlined in Chapter 1, followed by the results of the analyses of tutor responses to student writing and tutor interviews, and a discussion of the implications of these results for tutor practices in the virtual writing center and future research. This thesis culminates with a brief conclusion section, which summarizes and synthesizes the major findings and implications from both studies and offers directions for future research. 


\title{
CHAPTER 1
}

\section{STUDY 1: COMMENTING FORMATS IN FIRST YEAR COMPORISITION Introduction}

\begin{abstract}
Although electronic commenting has become more common in recent years, there is not much research that examines different electronic commenting formats available to instructors, the tools available in each format, and the ways students perceive commenting formats and tools. Some recent scholarship that does consider how students perceive instructor commenting tends to focus on different kinds of comments (Bean 2011), but not different formats and how those formats affect content. This kind of discussion also fails to take into account how students might read different kinds of commenting formats in different ways.
\end{abstract}

This study begins to address the gaps above by examining two different first year composition classrooms and the ways in which the content of instructor comments change when they use either the end comment or the in-text response format on two different assignments. In addition, student surveys were administered to both classes and a sample of six students was selected for interviews. Since student use of the virtual writing center is voluntary, getting students to commit to turning in two assignments, setting them up with the same tutor who then uses each commenting format, and getting them to participate in a survey and interview would have been especially challenging. Thus, the first year composition classroom provides a suitable environment in which to receive student response to the different commenting formats. 
The specific research questions explored in this chapter include:

(1) How are instructor comments in each format affected by genre change?

(2) Which commenting format do most students prefer? What are the reasons for their preference for one format over another?

(3) How do students read in-text comments differently from end comments and what changes do students plan to make after reading comments in each format?

(4) To what extent are instructors able to predict the ways in which their own classes respond to the different formats? What reasons do instructors have for determining which formatting style their students prefer?

What follows in this chapter is a discussion of the methods employed to answer these questions; the results of the analyses of instructor comments, student surveys, and instructor and student interviews; and a discussion of the implications of these results for instructor and virtual writing center tutor response to student writing and future research.

\section{Methods}

\section{Participants}

Instructors. Two composition instructors at the University of Louisville participated in this study, each commenting in two response formats. Instructor 1 $\left(\right.$ Casey $\left.^{1}\right)$ and Instructor 2 (Erica), were both female composition instructors in their midtwenties and in their second semester of teaching first year composition at the college level . Casey was second year Master's student in English with an emphasis in Literature and Erica was also a second year Master's student in English, but with an emphasis in Rhetoric and Composition. Both had prior experience tutoring in the University of Louisville's Writing Center and both were teaching only one composition class at the

\footnotetext{
${ }^{1}$ All names of instructors, tutors, and students have been changed to protect their privacy
} 
time of this study. These instructors were selected based on previous participation in a pilot study and because they both used a genre-based approach to teaching composition. Instructors were given $\$ 50$ each as total compensation for their time.

The assignments. Each instructor used in-text commenting for the first half of their students and end commenting for the second half for Assignment One. Then, for Assignment Two, they switched to end commenting for the first half of their students and in-text commenting for the second half. Thus, each student received two types of comments between Assignments One and Two. Assignments used for this study were major writing assignments ranging from 3-5 page length requirements. For one instructor, Casey, Assignment One was a "Narrative Claim"2 and Assignment Two was a "Profile." For the other, Erica, Assignment One was a "Literacy Narrative" and Assignment Two was an "Informational Report." Because of a difference in class size, Casey completed 42 total responses, 21 with in-text commenting and 21 with end commenting, while Erica completed 50 total responses, 25 with in-text commenting and 25 with end commenting. Thus, a total of 94 instructor responses to student writing, 46 in-text comment responses and 46 end comments, were collected and analyzed for this study.

Students. Forty-one first year composition students at the University of Louisville in two different sections of Intermediate Composition participated in this study. Six of these students (five from Erica's class and one from Casey's) participated in interviews. Only one student from Casey's class was able to participate in an interview because of scheduling conflicts and time constraints. All students were female first year students at the University of Louisville. One student was African American and five were Caucasian.

\footnotetext{
${ }^{2}$ This assignment was a revision of a personal narrative. Students were asked to make a thesis driven causal argument, which claimed that an event, person, or experience caused their interest in a stated academic field.
} 


\section{Procedures}

Instructors. Both instructors were told that the content of their comments would be analyzed, in addition to the collection of student responses to the different formats, and that this study would be coupled with a study done in the virtual writing center. Erica also participated in the Study One as a virtual writing center consultant, and was thus told that the primary purpose of this thesis was to determine the most effective way to respond to student writing in the virtual writing center.

Commenting Procedures. Instructors were asked to divide their students in half and respond to the first half of the students using end commenting and the second half of the students using in-text commenting for Assignment One. Instructors were not given exact definitions of these two commenting formats. Casey wrote end comments at the bottom of the student text, thus keeping her responses in one document. Erica created a separate document for end comment, thus making her responses separate from the students' texts. Both instructors used marginal bubbles only for in-text commenting. Neither instructor used track changes. Both instructors used the highlight tool in a few intext responses, and each time the reason for highlighting was explained in a marginal comment. Casey attached rubrics and a breakdown of student grades to all responses, both in-text and end comment formats. Erica did not include grades with either written response format. Instructors were not required to stay within a particular time frame when responding to student writing and did not receive training in either method.

Student Surveys. Students were told that the purpose of this study was to determine the most effective way for responding to student texts. They were given a brief presentation that called their attention to the two different commenting formats they 
received for their first two major assignments. The two kinds of formats (in-text and end comment) were explained to students and they were asked to complete a survey indicating their preferences and perceived effectiveness for each format. Students were given copies of their texts and instructor comments for each assignment, and then asked to review them and refer to them while completing the survey. Students were then given approximately 15 minutes of class time to complete surveys and were also given the opportunity to volunteer for individual interviews. From these classes, six students participated in interviews. Students were asked about their first impressions of each commenting formats, to point to a place in each text where they felt comfortable revising and also a place that seemed confusing or overwhelming, what they thought was the most important focus for revision, what they would do/did to revise the text, which of the texts was/would be most drastically revised, and which of the commenting formats they preferred.

\section{Comment Coding Analysis}

Defining a comment. One challenge of this study was determining what constituted a comment. Since multiple sentences (or T-units) were sometimes used to describe a single writing matter, the referent was used as the unit of measurement. The referent is the object or idea to which a word or phrase refers. Breaking down in-text comments was relatively easy but determining individual end comments was more challenging. This unit was appropriate for this thesis project because referents allowed for instructor responses to be broken down into comments focused on a particular idea that was discussed at the full-text, paragraph, or sentence level. A referent was judged to end whenever the idea being discussed by the instructor changed in terms of how much 
of the text was being discussed. For example, if the instructor was commenting on overall organization (one referent), and then she moved to discuss organization within a particular paragraph, it was marked as a new, separate referent. Figure 1.4 below shows a paragraph of instructor text was broken down into three comments according to referent. The numbers in brackets indicate the end of a comment, and the bold, italicized text highlights the object to which the comment refers. The number one refers to two interviews, number two refers to a particular source and three refers to sources more generally.

\section{Figure 1.4: End Comment Broken into Referents}

I think that having two interviews seems like a good choice for research because those two people who have experience in the profession might have different opinions on the way writing is used in the field. [1] However, from your report, I am not completely sure who Kenneth Bechtloft is and how he views complement, extend, contradict, agree, or disagree with other sources.[2] I think that you should try to incorporate more from your sources and put those different sources into conversation with one another. In other words, you should probably quote (or paraphrase) each source multiple times.[3]

Referent Types. Each comment was then coded by the type of reference: fulltext, paragraph, or sentence. One of this project's aims is to determine how changes in commenting format changes the ways in which instructors address global (full-text) and local (paragraph and sentence-level) concerns in student writing.

Table 1.1: Codes for Type of Reference

\begin{tabular}{|lll|}
\hline Reference & Definition & Examples from comments \\
\hline Full-text & $\begin{array}{l}\text { Tutor/Instructor addresses a concern } \\
\text { regarding the entire student text or } \\
\text { more than two paragraphs. }\end{array}$ & $\begin{array}{l}\text { You should consider moving these } \\
\text { two paragraphs earlier so that your } \\
\text { reader understands the duties of a } \\
\text { nurse practioner before you } \\
\text { describe her duties. }\end{array}$ \\
\hline Paragraph & $\begin{array}{l}\text { Tutor/Instructor addresses a concern } \\
\text { regarding one entire paragraph or } \\
\text { more than one sentence. }\end{array}$ & $\begin{array}{l}\text { In paragraph 4, you need to reduce } \\
\text { this quotation and add more } \\
\text { analysis. }\end{array}$ \\
\hline Sentence & $\begin{array}{l}\text { Tutor/Instructor addresses a concern } \\
\text { regarding one sentence, a part of a }\end{array}$ & $\begin{array}{l}\text { I like the way you introduce Smith } \\
\text { in the beginning of this sentence }\end{array}$ \\
\hline
\end{tabular}


sentence, a phrase, or a single word. Local punctuation and grammar issues were also considered to be sentence-level. before your provide the quote from him.

OR

This needs to be plural.

Comment Directiveness. As mentioned above, the referents did provide a way of breaking down instructor responses into comments. However, there was great variation in terms of depth and framing of feedback and writing advice, especially in some of the longer comments ranging from $80-130$ words. Five different categories of comments that varied according to their directiveness were noted: rewriting, suggestion, praise, question, and observation. Moreover, these five types varied by whether or not the instructor provided explanations. Below is a breakdown of types of comments.

Table 1.2: Codes for Degree of Directiveness

\begin{tabular}{|c|c|c|}
\hline Code & Definition & Examples from comments \\
\hline $\begin{array}{l}\text { Rewriting with } \\
\text { explanation }\end{array}$ & $\begin{array}{l}\text { Tutor/Instructor rewrites student } \\
\text { text or offers specific wording } \\
\text { with explanation. }\end{array}$ & $\begin{array}{l}\text { "economic" rather than just } \\
\text { outside, since you're } \\
\text { emphasizing cost }\end{array}$ \\
\hline $\begin{array}{l}\text { Rewriting without } \\
\text { explanation }\end{array}$ & $\begin{array}{l}\text { Tutor/Instructor rewrites student } \\
\text { text or offers specific wording } \\
\text { without an explanation. }\end{array}$ & I'd insert "usually" \\
\hline $\begin{array}{l}\text { Suggestion with } \\
\text { explanation }\end{array}$ & $\begin{array}{l}\text { Tutor/Instructor suggests a change } \\
\text { to text without making the change } \\
\text { or offering specific wording. }\end{array}$ & $\begin{array}{l}\text { You might consider breaking } \\
\text { this sentence into multiple } \\
\text { sentences if you want to keep all } \\
\text { this information. Or, you might } \\
\text { consider taking out some of } \\
\text { these explanatory phrases which } \\
\text { repeat main ideas in your paper. }\end{array}$ \\
\hline $\begin{array}{l}\text { Suggestion without } \\
\text { explanation }\end{array}$ & $\begin{array}{l}\text { Tutor/instructor explains why } \\
\text { he/she is giving suggestion. }\end{array}$ & $\begin{array}{l}\text { the paragraph on the UAE is a } \\
\text { great place to focus a lot more } \\
\text { attention }\end{array}$ \\
\hline $\begin{array}{l}\text { Praise with } \\
\text { explanation }\end{array}$ & $\begin{array}{l}\text { Tutor/Instructor lets student know } \\
\text { he/she is doing something well } \\
\text { and explains why or how that } \\
\text { student is doing something well. }\end{array}$ & $\begin{array}{l}\text { Another strong aspect of it is the } \\
\text { second half of the third } \\
\text { paragraph (on page 2). You get } \\
\text { into a lot of explicit details } \\
\text { about what goes in to running a } \\
\text { business. }\end{array}$ \\
\hline Praise without & Tutor/Instructor lets student know & Your details from the text are \\
\hline
\end{tabular}




\begin{tabular}{|c|c|c|}
\hline explanation & he/she is doing something well. & well-chosen and specific. \\
\hline Question & $\begin{array}{l}\text { Tutor/Instructor writes a question } \\
\text { instead of a statement }\end{array}$ & $\begin{array}{l}\text { What is the distinction between } \\
\text { a shaper and a chronicle? }\end{array}$ \\
\hline Observation & $\begin{array}{l}\text { Tutor/Instructor makes } \\
\text { observation about the text without } \\
\text { providing a suggestion or } \\
\text { correction. }\end{array}$ & $\begin{array}{l}\text { PURPOSE: To persuade that } \\
\text { skeptical reader that you meet } \\
\text { cultural diversity competency } \\
\text { requirements by sharing specific } \\
\text { and concrete details about your } \\
\text { life experiences. }\end{array}$ \\
\hline
\end{tabular}

Writing Topics. After instructor responses were divided into comments and coded according to that comment, they were then coded according to the writing topics discussed. There were four writing topics: audience, genre, rule/convention/strategy, and description. Comments were coded according to whether or not they addressed the topics below:

Table 1.3: Codes for Writing Topics Discussed

\begin{tabular}{|lll|}
\hline Code & Definition & Examples from comments \\
\hline Audience & $\begin{array}{l}\text { Tutor/Instructor addresses concerns } \\
\text { regarding audience or calls attention } \\
\text { to a potential reader's response to } \\
\text { student text. }\end{array}$ & $\begin{array}{l}\text { I don't know how strictly this } \\
\text { assignment should follow } \\
\text { "conference paper" format, but I } \\
\text { know as an audience member it } \\
\text { can be nice to have some tangible } \\
\text { structure to hold on to while at a } \\
\text { presentation. }\end{array}$ \\
& $\begin{array}{l}\text { Tutor/Instructor addresses concerns } \\
\text { regarding the genre of writing or the } \\
\text { specific assignment. }\end{array}$ & $\begin{array}{l}\text { I can't yet tell what argument } \\
\text { you're making through all of it. It } \\
\text { feels like an informational report, } \\
\text { rather than an argument essay, if } \\
\text { that makes sense. }\end{array}$ \\
& $\begin{array}{l}\text { I'm wondering if you need to cite } \\
\text { this so many times, especially } \\
\text { because most of the info seems to } \\
\text { come from the same page. }\end{array}$ \\
& $\begin{array}{l}\text { Tutor/Instructor provides a rule, } \\
\text { convention, or strategy about } \\
\text { academic writing that is not text } \\
\text { specific (i.e. general writing advice } \\
\text { for the future). }\end{array}$ & $\begin{array}{l}\text { Citations are important, but it's } \\
\text { also important to use them } \\
\text { rhetorically - you don't want a } \\
\text { parenthetical citation after every } \\
\text { single sentence. }\end{array}$ \\
& &
\end{tabular}


Description

\begin{tabular}{|ll}
\hline Description & Tutor/instructor provides a \\
& summative description of the moves \\
he/she sees the writer making in the \\
student text.
\end{tabular}

Student Surveys

Each student was given class time to complete a 20 question survey. Surveys began with a descriptive paragraph, explaining to students that they were being asked to compare the types of comments they received on the first two major assignments. These types were defined as "in-text (comments which appeared in bubbles in the margins)" and "end comments (comments which appear on a longer note, separate from the paper itself)." The survey began by asking students to indicate which kind of comments they received on Assignment One and on Assignment Two. Survey questions first asked students if they read comments for either Assignment One or Assignment Two right away. Then, a large portion of the survey questions asked students to compare the commenting formats and determine how they read comments, which format focused on which particular writing topics, and how the formats made them feel about revision. Students were also asked to explain why they preferred the commenting format that they did and to include any additional advantages or disadvantages involved with either format.

\section{Instructor Interviews}

Each instructor participated in an audio recorded interview for 30 minutes. Instructors were asked to discuss the ways in which they responded to student writing 
previous to the study, how their processes changed when they were asked to respond in either in-text or end-comment format, in which format it took longer to comment, and which format they preferred. They were also asked to determine in which format they provided the most praise, explanation, questions, higher order concerns, lower order concerns, and re-writing. Instructors were asked about which commenting style they perceive to be most effective for students, which format they believe students prefer, what they perceive to be the strengths and weaknesses of each commenting format, and which commenting format they believed was most helpful for first year composition. They were also asked to explain under what circumstances within the composition classroom they believe each commenting format is the most effective. At the end of the interview, instructors were asked again which commenting style they preferred and why.

\section{Student Interviews}

Six students were selected for individual 30 minute interviews based on willingness to participate. These interviews aimed at determining how students understood both commenting formats and why they preferred one to the other. Students were asked about their first impressions of each set of comments, to pinpoint areas that were either clear or confusing, what they would/did change in revision, and why they preferred one format over the other. Students were provided with hard copies of both essays with comments.

Results: How Did Format Affect the Types of Comments Instructors Wrote? Instructors made more in-text comments but end comments were longer

Table 1.4 indicates that in-text responses include an average of five more comments per response and nearly twice as many explanations compared to the end 
comment. Table 1.4 also shows that the length of individual comments in the end comment responses contained on average two and a half times as many words as each intext comment.

\section{Table 1.4: Characteristics of End Comment and In-text Comment}

\begin{tabular}{lrr}
\hline & End comment & In-text \\
\hline Average Number of Comments on Essay & 7 & 12 \\
Average Length of Comments (words) & & \\
& 36 & 14 \\
Grand Total & 336 & 583 \\
\hline
\end{tabular}

This data suggests that the in-text commenting format encourages instructors to provide more comments on a wider range of writing issues. In addition, the instructors in this study tended to explain their in-text comments, especially when they provided praise, suggestions, and re-writes. For example, Erica addressed concern that a student did not follow the assignment prompt in the following explanatory in-text comment:

I understand that music allows you to say things that words do not, but this assignment is concerned primarily with words and literacy, reading and writing. And by writing, I mean alphabetic writing, not music writing. So while this is a very interesting narrative, it does not directly address the assignment prompt. This comment pointed to a highlighted sentence of student text found in the conclusion paragraph, and could be read as a full-text concern because the instructor's comment focuses on the "interesting narrative" that strays from the assignment prompt. However, other in-text explanations were brief, such as "To make this transition clearer, you might want to repeat that she is freelance." This comment from Casey is rather directive and

\footnotetext{
${ }^{3}$ Based on responses written by Casey only
} 
corrective, but it also explains that the instructor is making this suggestion so that the student's writing becomes "clearer."

On the other hand, the end comment contained fewer overall comments per response but these comments were on average over two and a half times longer than the in-text comments. For example, a typical end comment from Casey looked like this:

You also want to focus on explaining quotes--what they mean in the context of this essay and your interpretation of them. For example, when Tori says "But there are some problems that just can't be fixed," what does that mean to you? It seems important, but it just gets left dangling at the end of the paragraph. As a reader, I want to know what your interpretation of the statement is.

Both instructors in this study used examples from student text in their end comments to make their comments more specific and contextualized. This reproduction of student text may have contributed to the longer word count in end comments. In this example, Casey explained what she meant by "explaining quotes," interpreted the student text she quoted, and provided an explanation for her suggestion by identifying her position as a reader who wanted to know more.

Most in-text comments were paragraph or sentence-level and most end comments were full-text

Table 1.5 illustrates that end comments provided over twice as many full-text comments compared to in-text comments, and that in-text comments included significantly more paragraph and sentence-level comments compared to end comment.

Table 1.5: Type of Comment Breakdown

\begin{tabular}{lrr}
\hline Referent & End comment & \multicolumn{1}{l}{ In-text } \\
\hline Full-text & $144(43 \%)$ & $57(10 \%)$
\end{tabular}




\begin{tabular}{lrr}
\hline Paragraph & $119(35 \%)$ & $228(39 \%)$ \\
Sentence & $73(22 \%)$ & $298(51 \%)$ \\
Grand Total & 336 & 583 \\
\hline
\end{tabular}

Overall, instructors provided nearly twice as many in-text comments as they did end comments on the same total number of essays ( 47 in each format). However, the majority of full-text comments provided in the end comment were praises without explanations $(\mathrm{n}=66)$, followed by suggestions with explanations $(\mathrm{n}=25)$. For example, Casey typically began her end comments with a full-text praise, such as "I enjoyed reading this revision of your personal narrative," while Erica often ended her comments with a full-text praise, such as "Overall, good work." The full-text comments provided by in-text responses were mostly suggestions without explanations $(n=21)$, followed by suggestions with explanations $(n=17)$, including only one praise without an explanation $(n=1)$. Thus, the referent breakdown in Table 1.5 suggests that the end comment does indeed provide more full-text comments, but the majority of these comments suggestions for revisions.

\section{In-text comments were more likely to be explained}

On average, the end comment format includes two explanatory comments per instructor response ( $\mathrm{n}=90$ in 47 total responses), and the in-text format includes four explanatory comments per instructor response ( $\mathrm{n}=170$ in 47 total responses). Although the in-text responses had significantly more comments with explanations, the end comments were often explained as well. However, there were less overall end comments than in-text comments, which may suggest end comments did not provide explanations when in actuality, they did. This distinction between the number of explanatory 
comments in each format is still important to note because it indicates that the larger number of in-text comments was reflected in the number of explanatory comments.

In particular, in-text comments that were praises were more likely to be explained compared to end comments that were praises. Table 1.6 shows a breakdown of the kinds of praise comments given.

\section{Table 1.6: Types of Praise}

\begin{tabular}{lrr}
\hline Type of comment & End comment & \multicolumn{1}{l}{ In-text } \\
\hline Praise with explanation & $24(18 \%)$ & $64(42 \%)$ \\
Praise without explanation & $112(82 \%)$ & $90(58 \%)$ \\
Total praise & 136 & 154 \\
\hline
\end{tabular}

An overwhelming majority of the end comments coded as praises do not provide explanations. The section above gave some examples of the most common kinds of end comment praises without explanation (i.e. "I really enjoyed reading your profile"), but an example of an end comment praise with explanation is: "I like how you focused not on the type of small business, but you generalized about common traits shared among small businesses." In this comment, the instructor explained how she understood the student's focus (generalized traits shared among small businesses) and why that focus was strong (because the student did not focus on a particular type of small business).

Like end comment praises, in-text praises are also more likely to be without explanations. However, $42 \%$ of all in-text praises do have explanations, and in-text responses also consist of nearly three times as many praises with explanations compared to those in end comment responses. In-text praises without explanations were typically specific and attached to highlighted sentences, for example "Great selection and integration of the quote." Praises with explanations were typically short but specific, for example "Excellent first few sentences that summarize just enough about the field with 
examples." In this comment, the instructor explained why the first few sentences were excellent, rather than broadly complimenting the introduction paragraph.

Overall, $18 \%$ of the praises in the end comment format had explanations, and $42 \%$ of the praises in the in-text format had explanations. For instance, only $13 \%$ of end comment full text praises had explanations while $80 \%$ of in-text full text praises had explanations. Table 1.7 displays a further breakdown of the kinds of praises with and without explanations in each format.

Table 1.7: Praise Referent Breakdown (percent refers to the overall percent of the comment within the particular referent. i.e. $13 \%$ of all full-text praise included explanations and $87 \%$ of full text praises did not include explanations)

\begin{tabular}{lllll}
\hline Condition & Comment & Full-text & Paragraph & Sentence \\
\hline End Comment & Praise w/ explanation & $13 \%(\mathrm{n}=10)$ & $20 \%(\mathrm{n}=8)$ & $30 \%(\mathrm{n}=6)$ \\
In-text & Praise w/ explanation & $80 \%(\mathrm{n}=4)$ & $55 \%(\mathrm{n}=41)$ & $26 \%(\mathrm{n}=19)$ \\
\hline
\end{tabular}

It shows that the majority of end comment praises were at the full-text level without explanations $(n=66)$, followed by praises without explanations at the paragraph level $(n=32)$. For example, a paragraph level praise without an explanation was "Your introductory paragraph ends with a strong sense of purpose and stance: 'My goal by the end is to better understand the role/responsibilities."' Here, the instructor points out where in the introductory paragraph the purpose and stance were strong, but she does not provide an explanation as to why or how the introduction is strong. Alternatively, the majority of in-text praises were without explanation at the sentence level $(n=55)$, followed by praises with explanation at the paragraph level $(n=41)$. Praises with explanations at the paragraph level tended to be brief and specific, "Excellent job setting the scene. I can actually 'see' these things happening, while praises at the sentence level did not have explanations but were specific. These examples tended to focus on correct 
formatting, transitions, word choice, and introduction of sources. For example, "Nice attributive tag, "Formatting looks nice, and "Good question.

One way praises without explanations were used throughout in-text responses was after the instructor made a comment about something the student was doing incorrectly, and then later identified a place in the text where the student did that same thing correctly. For example, in one in-text response, Casey made a comment (4) about a student's introduction: "Hold off on your opinion- show rather than tell something like this through your choice of details. Then, near the end of that same page, Casey highlighted one particular sentence and wrote in comment 9 "Good detail that shows" (underlining done by the instructor). Although the latter comment is more descriptive than explanatory, if read with comment 4 , the explanation carries over to comment 9 .

The data in Table 1.7 shows that in the end comment, full-text praises were more likely than paragraph and sentence-level praise to be explanatory, but overall most end comment praises were without explanation. Conversely, in-text praises at both the paragraph and sentence level were more likely than full text praises to be explanatory. The difference $(n=26)$ between praises with and without explanations in the in-text format was much smaller compared to the difference $(n=88)$ between with and without explanation in the end comment formats. Although there were less overall praises in the in-text format compared to the end comment, the quality of in-text praises in terms of explanations was much higher compared to the end comment, even though most of these in-text explanatory praises were at the paragraph and sentence level. Sentence and paragraph level praises might have been clearer because they were focused on smaller areas of text than full-text praises. However, the end comment did provide more full-text 
praises, even though they were rarely accompanied by explanations. The extent to which these full-text praises were useful depends on the instructors' goals for including them (i.e. while the full-text praises may not have explained what the students did well in a constructive way that indicated the strengths of their writing skills, these praises may have been important for boosting student confidence and cushioning more critical comments within broad praises).

\section{In-text comments had more question comments and instructor rewriting}

Table 1.8 indicates that there were significantly more question comments in the in-text format compared to the end comment.

Table 1.8: Questions and Instructor Re-writes

\begin{tabular}{lrr}
\hline Type of comment & End comment & In-text \\
\hline Question & $20(6 \%)$ & $98(17 \%)$ \\
Rewriting & $6(4 \%)$ & $89(15 \%)$ \\
Suggestions & $118(35 \%)$ & $173(29 \%)$ \\
Other & $192(55 \%)$ & $223(61 \%)$ \\
\hline
\end{tabular}

In-text questions ranged from those focused on encouraging more content ("You could say more about this. What kind of writing does a dietician do to prepare for these classes which I would assume are primarily oral presentations?"),to those offering to students a variety of potential choices ('Line of defense against what? Disease? Patients' discomfort? Lawsuits?"), to those that pointed to a gap in comprehension or a lack in clarity ("How does this fit into the day to day activities?"). Conversely, questions in the end comment responses often encouraged elaboration. For example, in one such comment Erica wrote:

You mention business plans (in the quote on page 2 from Hubbard), but you do not go on to explain what these plans are. What do these business plans do? What 
is their purpose? Who is the intended audience? What information do they include?

Furthermore, Table 1.8 shows that instructors rewrote student text far more frequently in the in-text format $(n=89)$ compared to the end comment $(n=16)$. However, both end comments and in-text comments provided an overall greater number of suggestions than rewrites. Some of the in-text rewrites were simply word replacements in which the instructor highlighted a word and provided a corrective comment. For example, in one comment Erica highlighted the word "is" and comment corrected it to "are." However, other rewrites focused on formatting or the works cited pages, in which case there were not always significant reasons to explain rewrites: "You need to include the name of the web page, but you do not need to include the web address. In several comments, instructors rewrote one example and then continued to point out where students needed to make the same kind of revision, but without making a correction. For example, in one response Casey said "Always introduce your quotes with a "Brittney says" or something similar. Then, later in the student text, the instructor wrote "Introduce quote. Thus, the instructor set up an example that showed the student how to introduce a quote "that she could follow as she revised the reset of her paper.

This data is difficult to interpret because one might assume that a format consists of more questions is less directive than a format with more assertions than questions, thus consisting of few (if any) rewrites, and that a format with few questions would be more directive with a greater number of rewritten comments. However, Table 1.8 indicates that the in-text format consists of more question comments and more rewrites than the end comment. Both of these numbers are significantly higher in the in-text format compared 
to the end comment. However, the fact that overall the majority of end comments are suggestions (35\%) indicates that instructors might be less concerned with asking questions and more focused on offering suggestions, in the end comment, rather than rewriting student text, especially since most rewriting occurs at the sentence level (as detailed below in Table 1.9).

Table 1.9 indicates that the vast majority of rewriting occurs at the sentence-level in both formats.

\section{Table 1.9: Instructor Rewrites at Full-text, Paragraph, and Sentence level}

\begin{tabular}{lrrr}
\hline Condition & Full-text & Paragraph & Sentence \\
\hline End Comment & $1(6 \%)$ & $3(19)$ & $12(75 \%)$ \\
In-text & $2(2 \%)$ & $5(6 \%)$ & $82(92 \%)$ \\
\hline
\end{tabular}

Yet, there were almost seven times as many rewrites at the sentence-level in the in-text format. These rewrites were often rather complex. In one typical example, in Figure 1.5 the student text said:

\section{Figure 1.5: In-text Re-write}

\begin{tabular}{|c|c|}
\hline $\begin{array}{l}\text { the Speed School of Engineering, fhared his expenience at CMTA with me He sad, "As an } \\
\text { engineer, you are always having to communicate with clients whether that be through email, }\end{array}$ & 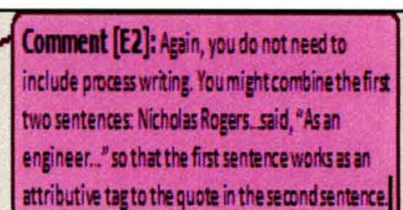 \\
\hline
\end{tabular}

The comment box E2 reads, "Again, you do not need to include process writing. You might combine the first two sentences: Nicholas Rogers...said, "As an engineer..."” so that the first sentence works as an attributive tag to the quote in the second sentence." This instructor's sentence-level rewrite highlights which part she understood as unnecessary "process writing" [the writer including too much of her own thought processes, illustrates exactly how the first two sentences could be combined, and explains 
how the sentences function together (one part as an attributive tag, the second part containing the quote). Although at the sentence level, this comment is dynamic because the instructor addressed multiple writing issues without changing referent. This kind of corrective comment can also serve as a model for other sentences with too much "process writing" commentary and in need of attributive tags.

\section{More in-text comments were rules and more end comments were observations}

Table 1.10 indicates that end comments included over twice as many observatory comments and in-text comments provided more rules/strategies.

\section{Table 1.10: Number of Rules and Descriptions}

\begin{tabular}{lrr}
\hline Type of comment & End comment & In-text \\
\hline Rule/strategy & 28 & 65 \\
Observation & 106 & 50 \\
\hline
\end{tabular}

Observational comments in the end comment consisted of the instructor summarizing the students' main arguments. For example, in one end comment Erica quoted part of the student's text and then wrote "I understand what you are trying to say, but it sounds like you began writing one sentence and switched to write a different sentence. In this comment, the instructor is not evaluating the student text, but rather providing her own observation of what she thinks the student's text seems to be doing. On the other hand, the in-text commented provided over twice as many comments that included rules or strategies compared to the end comments. One example of a comment that included general advice about all writing was: "Avoid second-person pronouns in this personal narrative. Use "I" instead. This comment suggests that the use of second-person pronouns is not appropriate for personal narratives. These kinds of comments offer writing instruction beyond the particular assignment and the student's current writing. Instead, the subject of the sentence is a writing concept, rule, or strategy rather than the exact 
content of the student's text. These comments are often attached to comments specific to student text, but can also be understood beyond the particular assignment.

\section{Results: How Did Students Respond to Different Formats?}

\section{Students prefer in-text comments to end comments}

Overall, this data indicates that students prefer in-text comments to end comments (the average preference for in-text comment over end comment on a 4-point Likert scale in which $4=$ definitely end comment and $1=$ definitely in-text was 1.56 ; standard deviation=0.89). Some students indicated on the survey that they preferred in-text comments because they made it "easier to locate and fix mistakes" or "revise the problems." Others appreciated having the comments "right at the site of the error," which for this particular student made it "easier to change it right then and there." One student suggested that the in-text comments helped her with revision because she said "I was able to...understand my mistakes better and [the in text comments] allowed me to create a better paper." Furthermore, two students noticed that in-text comments included both praise and criticism, because they pointed out "good and bad points and mistakes." Some of these students did not like the end comments because they found them to be too general, or "too vague and not specific enough." Perhaps for this same reason, other students disliked the end comment because it was not helpful in terms of revision. For example, one student said the end comment "doesn't help as much when I actually go to revise my paper," and another confessed "End comment makes me feel hopeless to change a problem that seems to have been strong throughout the entire paper." A third student explained the end comment as "more detailed and made it easier to understand my grade, but the in-text comments were easier when it came to revision." This particular 
student seemed to associate in-text comments with revision and end comments with justification for a grade. Furthermore, end comments were criticized for "leav[ing] out information because the teacher goes through and has to remember what she wants to say at the very end," which, according to one student, is an indication that the instructor sends a message that "less effort was put into reading your paper."

On the other hand, the students that preferred end comments appreciated them because "they were more broadly dealing with the entire paper"; provided "detailed explanations of what's good info[rmation] and what could use some work or needs to be taken out" and felt "more personal." While these students did not seem to criticize the intext comments, one student did refer to the in-text comments as "corrections," although this particular student also admitted to preferring them. Interestingly, some students mentioned that they would prefer a hybrid commenting format. For example, one student from Erica's class who circled "definitely in-text" as the format he preferred further explained "I actually think it would be most advantageous to use both in-text and end comments. That way nothing will be left out and that is how my papers have always been graded in the past." Another student, this time from Casey's class, said "I actually would like to see both on my papers. They both help me and they work well together. Grammar and such could be in-text comments and opinions or organization would be good in the end comment." This student seemed aware of the ways in which the comment format might be better for different kinds of comments.

\section{Students perceived end comments to be more confusing and less helpful for revision}

Table 1.11also shows that on average, students believed that end comments were more confusing, more wishy-washy, and most overwhelming. 
Table 1.11: Students' Average Perception of Format Preference and Confusion (average preference for end comment or in-text on a 4-point Likert scale: 4definitely end comment, 3-somewhat end comment, 2-somewhat in-text, 1- definitely in-text) ${ }^{4}$

Question

Average Standard Deviation

Which set of comments seems more confusing?

0.56

Which set of comments made you feel the most

overwhelmed?

Which set of comments seemed more wishy-

3.08

0.57 washy?

These ideas were reflected in their short answer responses as indicated above. One student explained the overwhelming aspect of the end comment as "pil[ing] every error on top of you at one time." Although most end comments in the sample I collected did include praise as well as suggestions for improvement, most of these praises were either at the beginning or at the end of the comment. This particular student seemed to appreciate the ways in which the in-text comments interspersed praise with suggestions.

Table 1.12 suggests that students identified in-text comments as more helpful in terms of revision, confidence, and clarity.

Table 1.12: Students' Average Perception of Formats and Revision (average preference for end comment or in-text on a 4-point Likert scale: 4- definitely end comment, 1 - definitely in-text)

\begin{tabular}{lrr}
\hline Question & Average & Standard Deviation \\
\hline $\begin{array}{l}\text { In which set of comments is it easier to see what } \\
\text { needs to be revised? }\end{array}$ & 1.34 & 0.69 \\
& & 0.95 \\
Which set was clearer? & 1.63 & 1.15 \\
$\begin{array}{l}\text { Which set of comments makes you feel more } \\
\text { confident about revising? }\end{array}$ & 1.59 &
\end{tabular}

\footnotetext{
${ }^{4}$ This same Likert scale was used for all student survey questions and displayed in Tables1.111.13 .
} 
Which set of comments helped you best understand

why you need to make the suggested changes?

1.98

1.10

Which set of comments made it easier to

2.07

1.10

understand the most important thing to change?

However, students indicated that in-text comments were slightly less useful in terms of helping them understand why they needed to make changes. This is reflected in the students' written responses about end comments mentioned above, which indicated that students appreciated the specific and detailed explanations in the end comment. In addition, students felt that end comments were only slightly more helpful in terms of identifying what the most important thing was to change. This is surprising, considering that one of the commonly understood strengths of the end comment is that instructors feel that they can prioritize (Bean 2011), whereas in-text comments make prioritizing more difficult for instructors to communicate. Thus, students might not be reading comments as legitimately ordered in terms of importance (some in the interviews mentioned end comments being in chronological order, when in actuality, they were not).

Students perceived end comments to more fully address content and audience matters and in-text comments to address organization and grammar

Table 1.13 indicates that students perceived in-text comments to be slightly more helpful in terms of organization and grammar, and end comments as slightly more helpful in terms of content and audience.

Table 1.13: Students' Average Perception of comment Formats and Writing Topics (average preference for end comment or in-text on a 4-point Likert scale: 4definitely end comment, 1 - definitely in-text) In which set of comments did you receive the Average Standard Deviation most help on... Organization? 
Grammar?

Content?

Audience?
1.39

0.80

2.17

0.95

2.51
0.81

Students' perception of in-text comments as more helpful with grammar and end comments as more helpful with content and audience is not surprising. However, the tendency for students to identify organizational comments with the in-text format was particularly surprising because organization is often considered to be a strength of the end comment, and a weakness of in-text comments. While the instructors may have in actuality focused on organization more in the end comment, the students' possible lack of awareness that end comments were focused on organization is significant.

\section{Results: How Did Students and Instructors Explain Their Perceptions of Different Formats?}

\section{Students}

Students strongly preferred in-text comments. Of the students interviewed, all six of them preferred in-text commenting. The most common reason students provided for this was the way the in-text comments were directly next to their own text, making it easier for them to see what needed to be fixed. Lisa explained, "I'm a very visual learner, so this is definitely more satisfying for me because I can see what I'm doing wrong at the exact position." She also said that she felt that as a writer new to college-level writing,

in-text comments were better for beginners: "I can see how the end comment would work really well with upper-level students, but I think for lower English classes a lot of people are still figuring out how to write academically, and I just feel like in-text is more nurturing that way." 
Lisa also acknowledged the way that some students might prefer the in-text comments so that they can simply "check off" the comments as they move through revision. In her interview Penny explained that she preferred in-text comments because “the arrows point to what needs to be changed and if it doesn't need to be changed, there's nothing there." In addition, Molly explained that "When you're revising, you want to do it quick, you don't want to reread your paper over and over again."

Another reason why many students preferred the in-text commenting format was because they appreciated receiving praise along with the criticism or suggestions. All but one student interviewed mentioned praise in relation to the in-text comments, and not the end comment. Julie explained, "I liked how she [the instructor] gave negative and positive feedback [in-text], it made me feel a lot more confident about my paper, rather than general stuff (Julie)." This particular student identified the following comment of praise to be especially helpful:

\section{Figure 1.6: In-text Praise Comment Identified by Julie as Helpful}

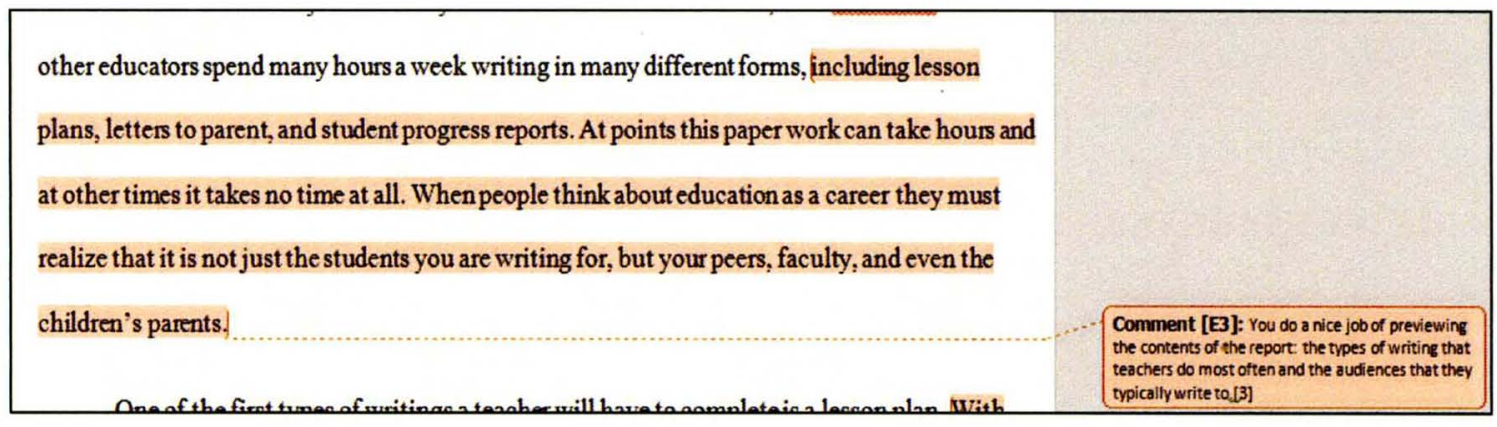

The small text box reads "You do a nice job of previewing the contents of the report: the types of writing that teachers do most often and the audiences that they typically write to." This student, along with several others, appreciated the way that her own text was 
highlighted in connection to this comment, and she was able to understand where and why she did something well. On the other hand, this same student was frustrated by the way that praise appeared in her end comment. She explained that

She [instructor] does add good positive feedback [in the end comment] but at the same time it's still too general for me to really see what my papers doing well, especially since the positive feedback isn't as long as the negative feedback and in the negative she's asking all these questions but in the positive feedback it seems like I did that.

The end comment to which this student was responding appeared like this. The comments that seem most clearly to be praises are highlighted:

Figure 1.7: Erica's End Comment with Praise Highlighted

You have a very interesting narrative about how your brother brought you into reading, and you do a good job of giving specific details and naming specific books that impacted you. You also describe the types of books that you like and how one kind of book lead to another for you. I like that you write about these books as kind of a rite of passage. These are the books that helped your brother, and now you, through high school, a very challenging time in anyone's life. And through these books you were introduced to more adults themes, and you were "ready for sad endings and shocking endings." You were all right without having a fairy tale ending.

I would like to hear more in your conclusion about what exactly Jeff's letter and those books did for you. You explain that your eyes had been opened to the "world of reading," but it seems too that your eyes were opened to adulthood, or at least a world where families are not normal, and endings are not always happy. These experiences also seem to demonstrate some importance in reading and telling your own stories. As you mentioned, you even started writing in your own journal. So while you say your eyes were opened to reading, what does that mean exactly? Certainly you read more because you can pick out what you enjoy, but what else can you say you learned from this experience? How does reading make you act or think differently?

Also, you might consider changing your title. You could say something about your brother changing your outlook/mindset or opening your eyes, but saying that he "changed your eyes" almost sounds like he plucked out your eyeballs and gave you new ones. :)

Overall, good work. 
While the comments of praise are contained within a greater observational paragraph, this student still found the praise "too general." The instructor did not explain why the student's piece was a "very interesting narrative," and perhaps in the second highlighted praise the student was unfamiliar with the idea of a "rite of passage" narrative. In addition, the student read the complimentary paragraph and the second paragraph as contradictory.

End comments lead to more drastic revisions of student texts. Despite Julie's frustration with the end comment, she admits that she more drastically revised this paper with which she received an end comment, in comparison to the paper which received intext comments. Julie was articulate about the way that her instructor's suggestion about the conclusion in the end comment caused her to revise. She explained that this was the most important thing she needed to revise "because I did start my introduction with this [how her brother brought her into reading], but then I didn't elaborate on it. So I needed to go back and add more about it in my other paragraphs." Yet, she also admitted, "I don't know if I was adding it to the right spot...the one with the end comment would be more drastically changed, but not necessarily for the better, it could be for the worse."

Similarly, Beth claimed that the end comment led to a more radically changed paper compared to the paper she received in-text comments on. Yet this student voiced extreme frustration with the end comment. She admitted "I was confused [by the end comment]...I felt it [the paper] flowed and things were in good order, but what I had to do, it really didn't give me a lot of detail as to what was wrong in the paper. I had to do another meeting with her [the instructor] to go through the entire paper." The comment Beth received appears below: 


\section{Figure 1.8: Casey's End Comment}

I enjoyed reading your profile and it has several strengths.

The biggest strength is the paragraph on your observation of the classroom and how you tie in one of the aspects you leamed in your interview with what you observed. In addition, all of your sensory and observation details add a lot to understanding what you explain about being a social worker.

Here are my suggestions for when you revise:

1. Try not to organize the paragraphs around "I asked X, she said Y." Find common trends and themes and organize paragraphs into those. You also seem to have many short paragraphs; finding and combining common themes will help make those shorter paragraphs into longer more detailed ones.

2. I would like for you to state your stance more clearly at the beginning of the essay-it seems to me that you focus most on the physical and emotional toll of social work. Go ahead and state that focus from the beginning and how it will relate to your evidence (interviewing an expert and observing a classroom).

While Beth did admit feeling comfortable revising "the stance part" in the comment labeled 2 by Casey, she said "the first comment was rocky" because "rewording the interview...I didn't understand what she [Casey] meant." Since the instructor did not write "reword the interview" in the comment labeled one in the above end note, then perhaps this was an explanation that came out of Beth's one-on-one meeting with her instructor. This student also admitted that she "literally gutted this paper" and that "I think the revision was a lot better than the original. [But] it did take more time I had to figure out how I was going to say the things we talked about without saying 'I said, she said." When asked about which commenting style she preferred, Beth said she definitely preferred the in-text but then mentioned, "of course, these comments at the very end make me work a little harder, but the in-text are better for me because I can go through the paper and see step by step what it is that needs to be changed."

End comments make students feel less motivated to revise. Although Beth more drastically revised her paper with end comments, other students voiced their frustration with the end comment which resulted in making them feel less motivated to 
revise. For example, Lisa admitted her frustration with the end comment which appears

below (highlighted text is the text the instructor cut and pasted from the student's own

text):

\section{Figure 1.9: Lisa's End Comment}

I think that you do a nice job of explaining how two literary works impact the way that you write, for better or for worse. You do a nice job of explaining what the books mean to you and how they work for you, but you do not spend too much time talking about the texts, something that is easy to do. You keep the narrative narrowly focused on these particular books, your experience with them and writing, and how these experiences seem to prepare you for writing in your intended career.

Near the end of your essay, you wrote, "Though I thoroughly enjoy English, it is likely that my current and future professor's will find my pieces slightly 'illegible', or a challenge at the least." You describe getting back an assignment and not receiving the grade that you expected. Can you say more about the assignment that you did? Can you include some specific comments from the instructor? You talk about this "challenge" in general terms. Can you provide more specific details?

Also, you need to be careful when using such extensive vocabulary because while it can make what you have to say more effective, it can also create, as you said, a challenge for the reader. Writing, especially in composition studies, business, new reporting, and other genres/fields, needs to be clear and direct. While the purpose of writing for entertainment, as in literature, may be to create interesting verbal plays, in many other types of writing, the purpose is to convey information in a way that is easy for readers to access.

You mention, "Most of my confusion derived from feelings that my heavy, or lofty wordiness made my argument understandable, when really it did the opposite." I would have to agree that your word choice does hinder readability at times. So instead of choosing a "lofty" word, simply use a word that is simple and easy to understand.

In the second paragraph, you wrote the following: "My two favorite books are $A$ Moveable Feast by Emest Hemingway and, The Stranger by Albert Camus. Both pieces are well respected in the literary world and PERTAIN inspiring stylistic choices; these two literary greats could not JUXTAPOSE or clash more heavily than they unfortunately do. Hemingway an American, and Camus a declared Frenchman both wrote noble pieces that were at times both autobiographical and fictitious, or simply either genre at once."

Instead of the word "pertain" (which means to relate or belong to), you should probably use "contain" (which means to possess or encompass). Also, the word "juxtapose" (which means to compare or put next to) seems awkward in this sentence because things cannot be juxtaposed or compared "heavily."

Qverall, very interesting self-reflective essay.

Lisa said that she spent more time revising this literacy narrative because she "spent a lot of time trying to figure out how to relate the comments [from Erica] to the piece and trying to underline where the issues were, in that regard." Even though a significant 
portion of this end comment is cut and pasted from Lisa's text, she went on to say them following:

Yeah, I definitely spent a longer time trying to figure out exactly what those comments meant in the end comment. Where...I guess when you're considering the actual revision of my writing I spent more time on the piece that had the intext notes because by the time I figured out what all the end comments meant, I was just kind of done with it (laughs)...But I was like this is already work in itself, so when I got around to the in-text ones it was just easier because I didn't feel so mentally exhausted.

Here, Lisa seems to find the process of going back to her own paper and matching up the instructor's comments with her own "underlin[ing]" time consuming and mentally exhausting. Molly seemed to share this feeling, admitting that the first time reading her end comment was "overwhelming" because it had "big bulky paragraphs... when you see something like this, you're like-I really don't want to read all this."

Students use a variety of strategies to determine their plans for revision. Near the end of our interview with Lisa revealed the two ways that she believes students decide what/how to revise. She first asked me what instructors seemed to prefer. I admitted to her that the two that I interviewed seemed to prefer the in-text commenting, but that they still felt pressure to write end comments. I also told her that most teachers feel that in-text commenting lends itself to lower order concerns, while the end comment focuses more on organization and global issues. Yet Lisa explained that when students chose to focus on grammar instead of more global issues, it was because they cared less about getting a better grade (and were thus less invested in revising), "I think anyone can 
pick up on the fact that a punctuation error is far less important than a structural error or any error with clarity, I guess it depends on how much you care about getting a better grade." This seems to hold somewhat true in the case of Penny, who was the least articulate student I interviewed. Penny had already revised her paper, and she explained that she focused her revisions on the comment that "talk[ed] about the actual argument itself, which is what the paper's about." Lisa also claimed that students who do want to revise determine what to revise based on the comments the instructor repeats in her response. She said:

As far as the revision of the piece as a whole goes, I think as long as they're more thorough comments about like the structure within the in-text revisions, then I think it works, at least for me, because even when she [the instructor] saw a problem with E12, that was a continuous seam, whenever she saw a problem with that, she would mark it again, so I think it just depends on, like the repetition. This particular student was able to prioritize which comment was most important by the number of times the instructor mentioned the issue throughout the in-text commentary. Lisa identified the following as the most important comment:

\section{Figure 1.10: Lisa's In-text Comment}

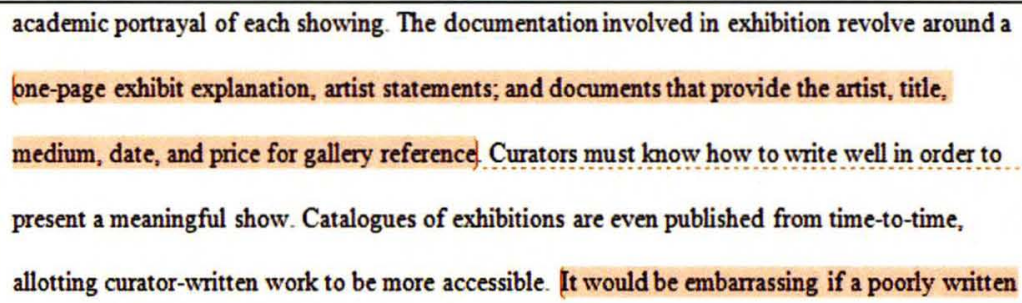

The comment box reads: "What exactly is included in the exhibit explanation and arts statements, and who reads them? Is the curator involved in writing the artist's statement?

What are the "documents" that include all the information that you list here. Say more 
about these different types of writing." Lisa explained that this comment had also appeared earlier (in E4, as "Say more about these. What are each of these statements exactly? What is included in each? Does the curator write the artist's statement? If not, what role does the curator play in getting that writing to the audience at the gallery") and then appeared later (in E18, as "What exactly do you mean?"). For Lisa, the repetition contributed to her awareness that clarity was the most important writing issue for her to focus on while revising.

In addition to these revision strategies, Molly claimed that she determined the most important writing issue to focus on during her revision by determining which of the end comments was the longest. Her end comment appeared as follows: 


\section{Figure 1.11: Molly's End Comment}

do a nice job of describing the different types of writing done in the field and explicitly stating some criteria for being successful as a writer in a nursing career (clarity and concision). You also do a nice job of explaining how important communication is because nurses do not always communicate face-to-face (because they work on different shifts). In this way, writing serves as the main medium for communication and a way for patients to receive consistent care. The formatting and citations in your report look clean and complete.

On the first page, you quote Laura Schneider, but that immediately raises the question, who is Laura Schneider? You explain who she in the next paragraph, but you should at least introduce her as a registered nurse (or by some other title) when you first use her as a source. You do a nice job of introducing quotations and using attributive tags through the rest of your report

You might also consider incorporating sources into the paragraphs near the end of your report, at the end of page 3 and on most of page 4. Did Schneider comment on how nurses e-mail other nurses and their supervisors or doctors about scheduling and other matters? Where did you hear about the importance of e-mail in nursing careers?

Make sure that pronouns agree in number with their antecedents (the words they refer to). At the very beginning of your report, you wrote, "A NURSE'S job consists of many things on a daily basis. THEY have to take care of THEIR patients, give them fluids, and check their blood pressure along with many other tasks." The plural words "they" and "their" refer back to the singular "nurse." You do this correctly on page 3, "That NURSE usually will write a letter to management. In that letter SHE has to properly communicate HER feelings in a letter and make sure HER feels are being conveyed properly." Because you used the singular "nurse," you used singular pronouns ("she" and "her") to refer back to the nurse.

Also, avoid making unnecessary shifts in person (from third person to second person). On page 4, you wrote, "That is why it is so important to focus in nursing school on being precise with everything YOU do." Who is "you" in this instance? You should continue to use third person pronouns (and nouns); use "they" and "nurses" instead of "you."

Overall very nice work.

Molly identified the $4^{\text {th }}$ paragraph as the place where she would focus the most on revision, and the second paragraph as the comment she felt most comfortable applying to her own revision. After I glanced at the comments, I felt that the third paragraph (highlighted) was the most global suggestion for revision. When I asked Molly if revised according to paragraph 3, she explained "I didn't focus so much on that because I felt comfortable with my sources...probably not my biggest problem area, I had more comments on this paragraph [paragraph 4], so I focused on this because it was the biggest paragraph." 


\section{Instructors}

Instructors believed their students were most confused by the end comment.

In alignment with the student survey and interview results, both Casey and Erica admitted that they believed students were more confused by end comments and instead preferred in-text comments. In particular, instructors felt that in-text comments were most helpful for students in terms of revision. Casey commented extensively on this issue, explaining that:

Especially for freshmen students [in-text commenting is more effective] because of their attitudes towards revision and their definition of revision. It's hard for them to get their minds around the generalizations you're making in the end comment but if you have specific spots in text its easier for them to go back and do something. It's kind of... It might not be ideal revision, but its better revision than you get with end comment because they actually do more, I think (Casey).

Casey was insistent about the need for in-text comments if a major goal in first year composition is for students to revise their papers. She also said that instructors should continue responding to students with the in-text comments until they change their definitions of revision in a way that acknowledges more global concerns,. Until then, Casey explained, students will not ever be "reached" by the end comment. However, Casey did admit that she believed end comments were better for work in progress for first year composition students because if she were to give them in-text comments, they: give them [students] the wrong impression because normally papers are not at the stage where they could benefit from just adding or subtracting in specific areas...students would definitely get the wrong impression about the 
draft... because you wouldn't be able to say they need to change their thesis or overall organization (Casey).

This suggests that Casey believed that in-text commenting was more suitable for papers nearer completion because they focused on "specific areas," whereas end comments focused more on higher order concerns, including the thesis and overall organization, and may offer advice for revision that changes the paper drastically. Thus, Casey seemed to favor in-text comments because they encouraged student revision and because students were more likely to revise successfully if she provided them with in-text comments instead of end comments.

In contrast, Erica began the interview admitting that she preferred in-text commenting but then by the end of the interview admitted to believing end comments were more appropriate. She explained that her students often felt that if they "fixed" what she identified in the in-text comments, then they thought their papers were perfect when in actuality there were far more issues than she was able to point out. Erica suggested that the end comment allowed her to suggest to students that they need to think of revision "on a larger scale." Like Casey, Erica identified the end comment as more appropriate for commenting on the thesis and organization, but Erica also mentioned three times during our interview that she felt she should prefer the end comment because it was "more teacherly." After further questioning, she explained that end comments encouraged students to think about their papers "in their entirety" rather than thinking "if I change this one word or cut and paste one paragraph" then revision is complete. However, Erica still seemed to prefer in-text commenting. She admitted, "I like in-text best. I think students like knowing exactly what they need to fix...If I were the student, I 
would prefer them." Thus, Erica's preference for in-text commenting seems directly related to her perception that students like them, and yet, felt that the end comment might serve students best.

Instructors found in-text comments easier to construct. In addition to finding in-text comments most helpful for students, both instructors admitted that in-text comments were easier for them to write in response to student texts. While Casey found in-text comments much faster than end comments, Erica claimed that she spent more time on in-text comments. Erica further indicated a significant difference in her processes for commenting using either in-text or end comment format:

I think I spend more time [overall] on in-text because I read slower, but in the end comment I feel like I'm writing paragraphs...[When I'm doing] in-text comments, I only read once and make the comments as I go so I read slowly, instead of reading and getting a feel for it and then responding" (Erica).

She also admitted that she spent more time reading student text when she wrote in-text comments, and she spent more time reading and planning her own comments (and less time reading the student text) when she responded with the end comment.

Casey's definite preference for in-text commenting contrasts significantly with Erica's "torn" feelings between the commenting formats, but eventual preference for the end comment. This is especially interesting because there were no significant differences in terms of how the different commenting formats affected the content of both instructors' comments. 


\section{Discussion}

These findings from student surveys and student and instructor interviews point toward a strong preference for in-text commenting. Most notably, the in-text format included shorter but more frequent comments and more question comments, but also a greater amount rewriting compared to the end comment. Additionally, the majority of both students and instructors preferred in-text commenting over the end comment because they felt that the comments were clearer and made revision easier. Yet, students admitted that their writing was more significantly changed when they revised using the end comment response. Both instructors also revealed during interviews that they preferred responding with in-text comments because they believed them to be more efficient and more helpful for student revision.

One of the most surprising findings of this study, however, was how much commenting format seemed to affect praise and how students used that praise to guide their revision and writing development. More specifically, this study revealed that praise was more frequent in the end comment but more explanatory in the in-text comments. Furthermore, students acknowledged and claimed to use the praise they received through in-text comments as they revised their writing and seemed to overlook praise in the end comment. The findings from this study complicate Dweck's (2007) concept of "process praise," which she says motivates students by acknowledging their persistence, effort, engagement, and improvement. While the findings from this study support Dweck's claim for the importance of process praises and the need to encourage motivation, these findings also suggest that process praise must be clearly articulated with specific 
references to student text and explanations of how and why student writing is working effectively in order for praise to be most productive.

In examining these findings, it might first prove helpful to re-examine the ways in which we use praise as a tool to improve student writing. Rather than using praise for just motivation and confidence building, the results from student interviews suggest that students might actually be using praise to help them understand what they are doing well not only in the particular places where instructors praise the, but throughout the entirety of their own texts when they write in similar ways. In addition, students seemed to acknowledge praise more frequently in the in-text comments, which means that constructing explanatory praise in the end comment is essential to facilitating student revision.

On a separate note, student and instructor preferences for in-text commenting because of its perceived effectiveness in terms of revision must be reexamined in light of the findings from student interviews, which suggest that students more drastically revised when they received end comment responses to their essays. While students indicated that they were less comfortable making changes to their writing using end comment responses from their instructors because instructor expectations were not always clear, they also seemed to spend more time on revising and rewriting. Since the end comment does make the process of "finding and fixing mistakes" more difficult for students, some indicated that they spent more time trying to interpret these comments than they did revising their own essays. This begs the question: Is it the instructor's job to locate issues in student writing and the students' job solely to make revisions, or should instructors be teaching 
students to locate their own writing issues and then determine ways to revise them on their own?

Of course there are limitations to this study that open up questions for future research, the most significant of which is the size of the study and the amount of time in which it took place; only two instructors, both of which were new teachers, and only first year composition students participated in this study. Additionally, interviewing more students, especially those who preferred end comments ${ }^{5}$, would provide more information about how students use instructor comments in each format. In addition, this study would have benefited from analysis of student texts both before and after revision based on instructor comments would provide a clearer idea of what kind of revision (if any) occurs after instructors respond in either format. More research is also needed on the ways in which students of varying degrees of college writing experience and understand different commenting formats, and on the ways these commenting formats function in response to different genres and disciplines.

In other words, this study does not indicate which commenting format leads to the most significant revisions. However, it does indicate the preferences students and instructors have in terms of commenting formats and the perceived affects they believe these formats have on writing. Overall, however, the most striking finding about instructor response to student writing is this: in-text commenting includes a higher quantity of overall comments, explanatory praise, question comments, and rewriting of student text and both students and new instructors seem to prefer in-text commenting over the end comment.

\footnotetext{
${ }^{5}$ Unfortunately, none of the students who volunteered for interviews preferred end comment responses to their writing.
} 


\section{CHAPTER 2}

\section{STUDY 2: COMMENTING FORMATS IN THE VIRTUAL WRITING CENTER Introduction}

In addition to the first year composition classroom, the virtual writing center is another context in which responding to student writing electronically occurs frequently. Although scholarship on virtual writing centers has primarily focused on synchronous online procedures (Beach, Anson, Breuch, \& Swiss, 2002; Hewett, 2006), Neaderhiser \& Wolfe's (2009) recent findings suggested that over $90 \%$ of online consultations use asynchronous methods. Knowing that email format is the most popular method might seem conclusive, yet there are various technological options within the email format which need to be considered. Tutors use a variety of asynchronous techniques, such as track changes, comment bubbles appearing in the margins of student texts, end comments, and separate letter/response documents. However, little research has been done to determine which commenting strategies are most effective for both tutors to construct and students to read. Furthermore, the processes tutors go through and the difficulties they encounter as they write email responses in different formats have not been explored.

This study begins to address the gap in recent scholarship on asynchronous virtual writing center response formats by examining responses written by five writing center 
tutors using the same formats as the first study (end comment and in-text). These tutors were also interviewed and asked to discuss both their processes and preferences.

The specific research questions explored in this chapter include:

(1) How do the processes tutors use in the virtual writing center change depending on the format of their response?

(2) What strategies do tutors use to overcome the limitations of either the in-text of the end comment format?

(3) In what ways will tutors resist, embrace, and/or change their approach to virtual writing center responses throughout this study?

\section{Methods}

\section{Participants}

Tutors. All five virtual writing center tutors who worked in the University of Louisville's writing center participated in this study and each conducted seven tutoring responses of each format type. Thus, 14 responses ( 7 in-text and 7 end comment) were collected from each tutor. Tutors were selected based on willingness to participate in the study. Four of the tutors were female (two were second year Master's students pursuing degrees in English and two were second year doctoral students in the English department), and one of the tutors was a male who was also a third year doctoral candidate in the English department. All of these students were also teaching one class at the time of the study, and three of them had at least two years of teaching experience at the college level. 
Clients. Client permission was not required for this study because it focused on tutor comments rather than student text. There were 9 different students whose texts were used for this study. Four of these students were graduate students, one was a nontraditional student ${ }^{6}$, one was a freshman, two were sophomores, and one was a junior. Four of these students were non-native English speakers and five were native speakers of English. Of the classes from which these essays were submitted to the virtual writing center in this sample, one was a from an English class, one was from Sports Administration, one was from Communications, one was from Human Development, one was from an Educational Leadership class, two were part of a Humanities thesis chapter, one was from a history class, one was a personal statement and one was from a Humanities class. The ages of these students were unknown.

\section{Procedures}

Tutors. All tutors were told that the content of their comments would be analyzed, in addition to a second part study with the same commenting formats in the first year composition classroom with instructor comments and student responses to the different formats. Tutor 4 also participated in the Study One as an instructor. Tutors were asked to complete 7 virtual writing center responses in each of the two formats and they were given the option of which format to begin the study using. Tutors were not given exact definitions of these two commenting formats, but they were told that in-text formats should primarily use track changes and marginal comment bubbles and that end comments should primarily be completed on a document separate from the student text. All virtual responses included a cover page explaining to the student how she/he should

4. Since these students are usual adult students with some experience with college work and significant professional experience, I considered them to be graduate students in this study. 
read the virtual responses. Depending on the tutor, these cover pages ranged from very brief explanations without mention of the student's particular text to over a full page which included a short summary of the tutor's primary observations of the student text in addition to the explanation of how to read the response.

On the other hand, when tutors were asked to construct end comments that had few or zero in-text comments in the form of minimal marking, nearly all of the tutors struggled to resist in-text commenting, and thus ended up providing almost as many intext comments as end comments. Alternatively, some in-text responses were accompanied by an email to the student in which the tutor attempted to prioritize his/her comments for the student to read before reading the in-text comments. These responses were eliminated from the study because they seemed to be too much of a "hybrid" model, making them difficult for analysis in this study.

\section{Comment Coding Analysis}

This study used the same referents, coding category definitions, content codes, and types of comments as those outlined in Chapter 2, Study 1.

Analysis of tutor responses. A total of 70 virtual writing center responses with comments were collected. A sample of 10 responses (two from each tutor, one in each format) was coded. Responses were examined for both differences and similarities between the in-text and end comment formats. An analysis of common trends in tutor responses collectively were considered, as well as the ways in which each individual tutor changed his/her response when the commenting format changed.

\section{Tutor Interviews}


Interviews were audio recorded and analyzed for both commonalities among tutors and differences in terms of approaches to using each commenting format, perceptions of how students understood their comments, reasons why tutors commented the way that they did, and preferred commenting format. These interviews were conducted with the goal of determining the tutors' processes and perceptions of their commenting styles when using two different formats.

\section{Results: How Did Format Affect the Types of Comments Tutors Wrote?}

\section{Tutors wrote more in-text comments but longer end comments}

Table 2.1 indicates that the average number of comments in the in-text virtual writing center response contained over two and a half times as many comments as the end comment. Yet, the average number of words in end comment was nearly three times as many as in the in-text comment. Thus, the end comment responses tended to be fewer but longer and the in-text comment responses tended to be more frequent but shorter.

Table 2.1: Characteristics of VWC End Comment and In-text Comments

\begin{tabular}{lrr}
\hline & End comment & In-text \\
\hline Average number of comments in response & 10 & 27 \\
Average length of comments (words) & 48 & 19 \\
Grand Total & 68 & 136 \\
\hline
\end{tabular}

This difference in commenting formats appeared like this: 
Figure 2.1: Sample VWC End Comment

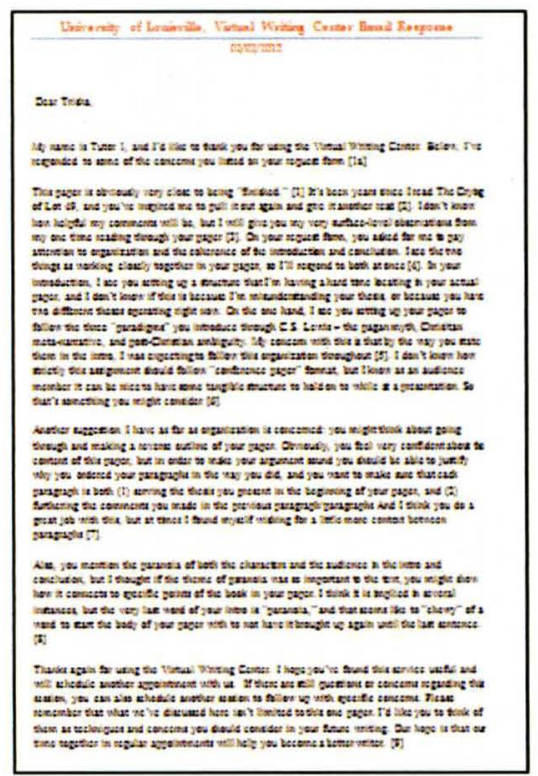

Figure 2.2: Sample VWC In-text

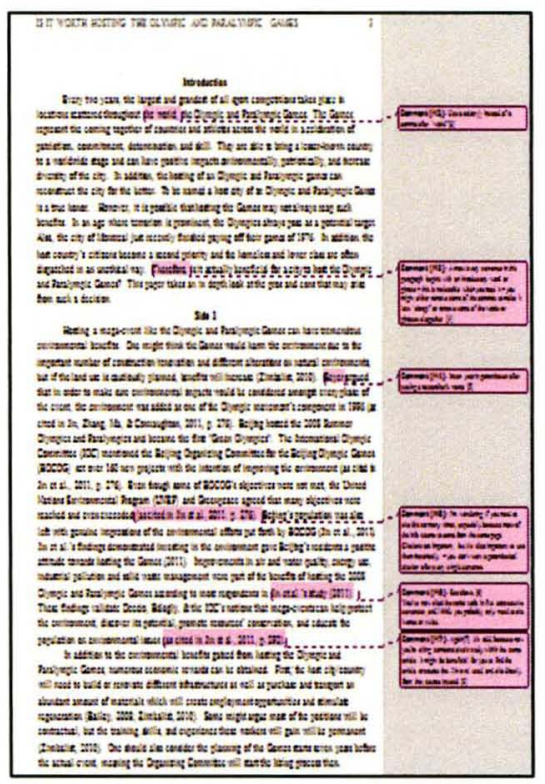

Although the majority of end comments appeared in a format similar or exactly as the one above, two of the tutors used an end comment template developed by the University of Louisville's Writing Center called the Standardized Asynchronous Response (SAR). This template encouraged tutors to consider particular higher order concerns, but tutors were not required to use it and were also encouraged to use the template with much flexibility. 


\section{Figure 2.3: Sample VWC End Comment SAR}

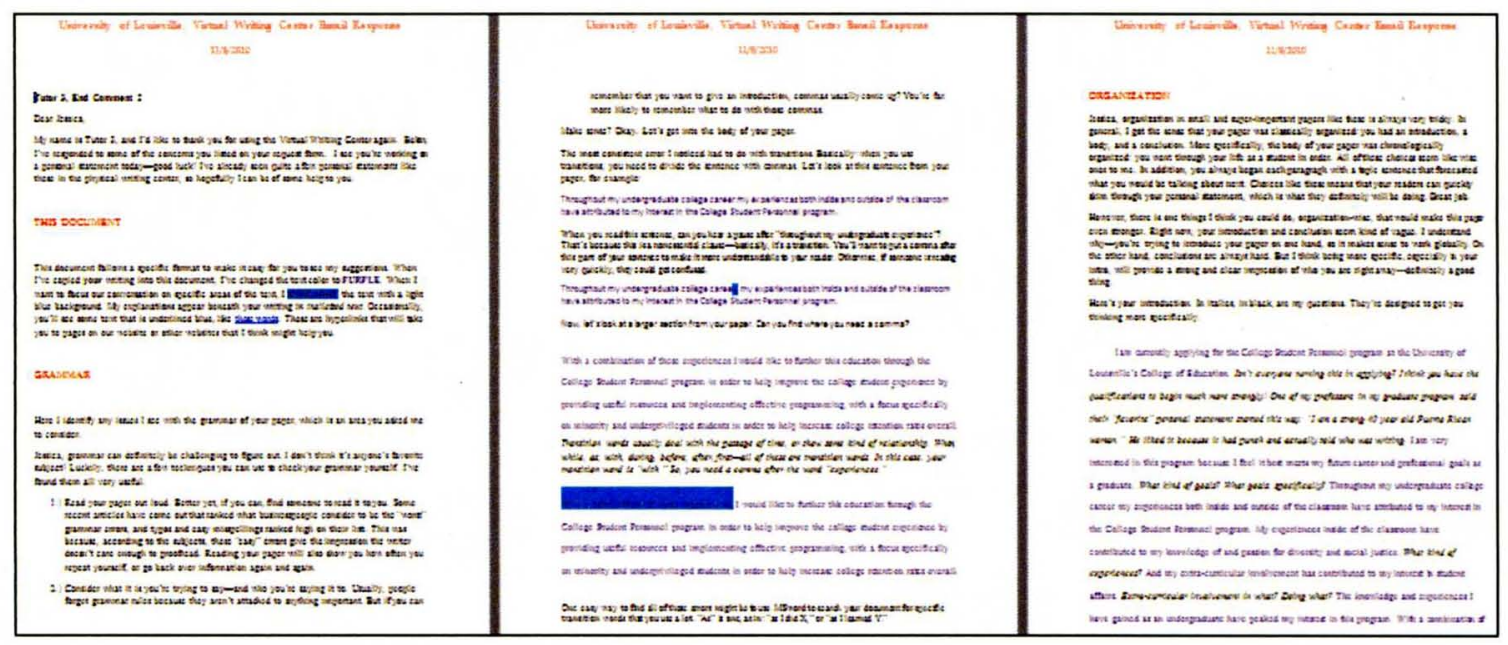

As shown above, the SAR followed a letter format with bold, capitalized red headings which, in this particular example, read "This document," "grammar," "organization" and "relevance/answering all the questions," and "future work." In this example, Lindsey cut and pasted examples from the student's text into the end comment document, which was common among all of the tutors and also added to the overall length of the end comment.

\section{More in-text comments were sentence level and more end comments were full-text}

Table 2.2 shows that the end comment responses included nearly twice as many full-text comments overall compared to the in-text formats. In addition, these full-text comments made up $66 \%$ of all end comments. In contrast, the in-text format had nearly eight times as many sentence-level comments compared to the end comment format, culminating in $69 \%$ of all in-text comments. The difference in terms of paragraph level comments between the two formats was insignificant.

Table 2.2: Type of Comment Breakdown

\begin{tabular}{lrr}
\hline Referent & End comment & In-text \\
\hline Full-text & $45(66 \%)$ & $23(17 \%)$ \\
Paragraph & $11(16 \%)$ & $19(14 \%)$ \\
\hline
\end{tabular}


Table 2.3 indicates that over half the explanatory end comments are full-text referents while nearly two thirds of the in-text explanations are sentence-level referents. Table 2.3: Overall Explanatory Comments by Referent

\begin{tabular}{lrr}
\hline Referent & End comment & In-text \\
\hline Full-text & 14 & 7 \\
Paragraph & 4 & 5 \\
Sentence & 5 & 19 \\
Grand Total & & \\
\hline
\end{tabular}

Praise was infrequent with the exception of one tutor

In the previous study described in Chapter 2 of this thesis, instructors' use of praise was incredibly frequent, even though not all praises had explanations. However, in this study, praise was comparatively infrequent $(n=17)$. In addition, $41 \%$ of the total praises $(n=7)$ came from Lindsey, and all of the praises which included explanations ( $n=3)$ were given by Lindsey. One example of explanatory praise from Lindsey's end comment response was:

[Name of student], you've given me great specific and concrete detail in this section-it says a lot about you as a person, too. Using the story of this son really does a lot to draw your reader in and make them understand just what kind of person you are.

In this praise, Lindsey explained to the student not only that his detail was "concrete and specific" but she also suggested that this kind of detail was important because it "draw[s] the reader in and make[s] them understand." Thus, the comment suggested that the detail 
was effective because it drew in the audience and also provided information about this student's personal character.

\section{More in-text comments were instructor re-writes and questions}

Table 2.4 indicates that tutors provided over four times as many question comments in the in-text format compared to the end comment. Similar to the question comments provided by the instructors in Chapter 2 of this dissertation, often times these question comments offered students multiple choices for revision, asked several questions at once, and asked clarifying questions. For example, in an in-text response, Scott asked "Is this your thesis? Or is the first sentence your thesis? Does it represent an opinion, or some sort of narrowing down of the overall topic of the Crisis? What is the particular angle on the crisis that you're going to talk about?" In this question comment, Scott suggested that the thesis statement needed clarity. These questions encourage the student to figure out which statement is her thesis, what kind of statement (opinion or narrowing down) that thesis is, and what kind of angle she wants to discuss. Another example of an in-text question comment comes from Alice, who asked a question clarification comment and also provided the students with options for revision, "Do you mean the social worker? Social work would be the label for the field as a whole, while the social worker would designate the individual doing the work in the field. If you mean 'worker,' you should double check that it's correct throughout your paper." In this sentence-level referent, the tutor explained to the student the different implications involved in using "social worker" and "social work" and also encouraged her to be consistent throughout the entire essay. 
Similarly, the end comment question comments also encouraged elaboration but oftentimes included an observation first. For example, Erica wrote, "You mention that you would like to work with children, but can you say more about that? Do speech pathologists specialize in different areas? If so, can you say more about those? Are there specific groups of children or specific speech disorders that you would be more interested in working with?" In a different end comment question comment, Alice used minimal marking and font color to indicate places where one student seemed to leave out important information for comprehension. Alice's end comment read "In your paper, I've marked places where you seem to have left out some information with question marks in brackets, like this: [??] and changed the text to be blue. Her in-text markings looked like this:

\title{
Figure 2.4: Alice's Minimal In-text Marking
}

\begin{abstract}
supplies. or [??, who is moving in?] move in because of high crimes in the area. Parents would worry about the future of their children in those neighborhoods. Those worries on daily basis would shorten one live or causes heart attack.

Base on Michael Omi definition of race, [?? what is "socio-historical"? what are you describing?] socio-historical by "which racial categories are created inhabited, transformed and distroyed". So to tied this video together with the article of race, there are much correlations that race was some thing that was fixed and be used against the people of color or minorities by the one who in control of power. This was meant to reduced the
\end{abstract}

Although these question comments go beyond minimal marking, Alice's decision to explain the overall writing issue trend in the end comment and then to mark the places in text suggest a possible strategy which can be used to overcome the limitations of the end comment format.

Table 2.4 also indicates that tutor rewriting of student text occurs over five times as often in the in-text commenting compared to the end comment. The majority of rewriting in both response formats occurs as the sentence level. For example, a typical 
rewritten comment for Scott was “'marked by' might be stronger." In this instance, Scott did not literally rewrite the student text but he did provide a phrase which could immediately replace the student's text without the student needed to do work other than deleting the word of her text highlighted by the tutor and replacing it with the tutor's phrase, which the student most likely assumed was a better fit. This same kind of rewriting also occurred in end comment responses, even though such comments were significantly less frequent. For example, Erica wrote "Be sure to tell your readers specific things about you that they did not already know. So you might begin by saying something like this: "I am applying for a master's degree in speech-language pathology because..." While this is only a partial sentence, this comment still provides the student with words imagined and constructed by the tutor which the student could (and most likely did) cut and paste directly into her draft, which is a kind of rewriting of the student paper.

Table 2.4: Questions and Tutor Re-writes

\begin{tabular}{lrr}
\hline Type of comment & End comment & \multicolumn{1}{l}{ In-text } \\
\hline Question & $8(12 \%)$ & $34(25 \%)$ \\
Rewriting & $9(13 \%)$ & $51(37 \%)$ \\
Other & $51(75 \%)$ & $51(38 \%)$ \\
\hline
\end{tabular}

Of these rewritten comments, $56 \%$ of the end comments $(n=5)$ and $92 \%$ of the in-text comments were at the sentence level. Both the end comment and in-text formats had the same number of paragraph level $(n=2)$ and full-text $(n=2)$ rewrites.

\section{More in-text comments were observations and rules}

Table 2.5 indicates that the in-text format included more observation comments and writing rules.

Table 2.5: Observation comments and general writing rules

\begin{tabular}{lll}
\hline Format & End comment & In-text \\
\hline
\end{tabular}




\begin{tabular}{lrr}
\hline Observation & 10 & 15 \\
Rule & 5 & 11 \\
\hline
\end{tabular}

However, observation comments in the end comment were on average 69 words per comment compared to an average word length of 18 in the in-text format. These observatory comments in the end comments were usually summative paragraphs in which the tutor explained how he/she understood the student's major claims in the text. For example, Molly wrote the following end-comment observatory comment:

In your introduction, I see you setting up a structure that I'm having a hard time locating in your actual paper, and I don't know if this is because I'm misunderstanding your thesis, or because you have two different theses operating right now. On the one hand, I see you setting up your paper to follow the three "paradigms" you introduce through C.S. Lewis - the pagan myth, Christian metanarrative, and post-Christian ambiguity. My concern with this is that by the way you state them in the intro, I was expecting to follow this organization throughout In this comment, the tutor admitted her confusion with the ways in which the writer structured the piece yet she prefaced those concerns with "I see you setting up..." which suggested to the writer feedback about how his/her writing was perceived by the tutor. While the end comment observations tended to be significantly more summative, the intext observations were shorter and more connected to reader expectation. An in-text observation comment written by Erica was: "From this paragraph, I assume that you are going to discuss all three pieces that were part of the recital, but this is not the case." In this instance, the tutor described how she thought the student's essay was going to play out, but then admits "this is not the case." This kind of observation suggested that there was an issue in terms of the introductory paragraph and the content of the essay, yet in 
this comment the tutor attempted to bring this observation to the tutor's attention, rather than offering a way for her to rewrite or revise the sentence.

In addition, Table 2.5 also shows that there were over twice as many writing rules included in the in-text comments compared to the end comment. In response to one student's claim that "Due to the importance of eye contact in the western society this conduct must led [sic] to false impression when socializing with new people," Alice highlighted the word "must" and wrote "Must suggests that it always will lead to misunderstanding. Generally in academic writing, the writer will offer a more tentative phrase, saying "'might lead."' In this comment, Alice offered advice about "academic writing," which, although related to the student text, was also framed outside the context of the particular piece of student writing. Instead, the focus is on the concept of "academic writing."

\section{The role of instructor or tutor changes comment content}

Table 2.6 indicates that the content of Erica's responses was affected by her tutor or instructor position in relation to the student text. She provided more praise, fewer questions, and less rewriting as an instructor.

Table 2.6: Erica's Comments as Instructor vs. Tutor

\begin{tabular}{lrr}
\hline Type of comment & Instructor (\%) & \multicolumn{1}{c}{ Tutor (\%) } \\
\hline Praise & 19 & 7 \\
Question & 13 & 22 \\
Rewriting & 16 & 22 \\
& 52 & 49 \\
\hline
\end{tabular}

\section{Results: How Did Tutors Perceive Different Formats?}

By the time tutors were interviewed, they had been participating in this study for

five months and many of them had completed or had nearly completed seven responses in 
each of the two formats. Thus, these tutors were able to articulate the ways their processes changed depending on which format in which they were writing. Perhaps because of their experience with each format and the absence of a collective tutor training in each format, these processes were nuanced and individualized, which made identifying trends among practices challenging. Yet, there were some commonalities in terms of understanding the role of what the tutor should be doing for students using the virtual writing center, even through processes and preferences were rather varied.

\section{Most tutors prefer writing in-text responses}

Before participating in this study, three of the five tutors (Mary, Alice, and Erica) preferred in-text commenting in the virtual writing center. For Mary, this process was "more natural" and allowed her to provide an "in-depth, line-by-line reading of the student paper which they deserve... and it allows you to really dig deep and look at these, which I think is very important, stylistic issues and it allows you to be really precise." In addition, Mary preferred the in-text because she felt that she spent more time reading the student text, while the end comment took longer to right the comments. Also, Alice preferred in-text commenting because it allowed her to respond as she was reading the paper and because comments are then "visually right there so students don't have to go digging and guessing about where the thing your commenting is or how many times they do it." Similarly, Erica preferred in-text commenting because it allowed her to make comments when she saw them rather than having to rely on her memory. In contrast, Lindsey had only ever done the end comment response in the virtual writing center and had not thought much about changing her style, and Scott strongly preferred the end comment response because of his own commenting style, explaining that he had "a 
tendency to be heavy handed and I care very much about style and language as a poet...I have to recognize my weakness which his I want to fix sentences and that misunderstands the purpose of working in the writing center."

After their participation in this study, two of these tutors changed their preferences, but three out of five still preferred the in-text format. Alice changed her preference from in-text to end comment over the course of the interview, and explained that, "I think 30 minutes ago I would have just said [I preferred] in-text because its faster, easier, more natural because I can just be a responder...but I think that, I guess after answering your questions and thinking about it more I think maybe that the comprehensive note is better." In contrast, Lindsey changed her preference from end comment to in-text because she felt that "being a reader is a way for me to ameliorate some of that stress so I can just be a reader instead of an instructor but I can't deny that its faster and I've got lots to do."

While these tutors all had preferences before and after participating in this study, they also felt the need to include a combination of both formats. Most commonly, this preference was for mainly in-text comments with a short summative end comment. Most tutors felt the need to write this way so that they could explain to students how to "explain how the [in-text] comments work... and to wrap it up" (Lindsey) or as a way to summarize which then "allow[s] the student to see that they shouldn't despair about all the comments I made." Less often, tutors preferred to write a longer end comment with a few in-text comments to serve as examples to which they would refer within the end comment.

\section{Physical and spatial constraints affect commenting style}


Some tutors mentioned the ways in which the spatial conditions (most notably, the text boxes in the in-text format or the end comment's seemingly limitless space) of either format significantly affect the way responses are constructed. Mary explained her confusion over to what extent the text boxes should determine the length of her comments, and also her struggle to keep her end comments within 2-3 paragraphs, rather than going onto a second page response. She admitted that the end comment seems to lend itself better to explanatory comments, because:

there isn't the physical like spatial constraint [in the end comment]... you feel like you have to cut your text short in the in-text [format] because you realize your taking up most of the margin in the page and that's ridiculous. Trying to focus on two to three major issues in the end comment and really expanding, then in the intext there are lots of useful suggestions but not going in depth into why it's important to change this...

Likewise, Scott expressed his concern for end comments that are too long, voicing that students would most likely not know what to do with so much feedback and that only those highly invested would be willing to "figure out" these kinds of comments. Lindsey, whose end comment responses tended to span over several pages, claimed that she appreciated the ways the in-text comments encouraged her to "push myself to be brief [and] get right to it."

\section{The end comment is more future oriented and should be placed on the student text}

Despite the overall preference for in-text commenting, most tutors identified strengths of the end comment which were more difficult to accomplish in the in-text 
format. For example, Scott explained that end comments encourage a kind of "moving forward," because:

when you fix a line in a text it's a backwards looking thing, you do this, we're fixing this, but when the comments are at the end it's the whole process takes on a different temporality, 'I'm telling you this so you can do this in the future' so it pushes forward instead of staying back in what they did last week

Mary also recognized the way the end comments encourage movement forward, and she seemed to feel that making this kind of move in commenting was "instinctual for teachers." She expressed an almost moral obligation to provide students with feedback in terms of next steps to be taken in their revision process, explaining that "We do feel like, especially because we're instructors too, a need to give some kind of summative remarks... I would not feel right...without giving some directive comments at the end saying this is where you should go from here."

Tutors also had strong feelings about how the end comment should appear in relation to student text. Mary said the end comment should "go directly on the draft not a separate sheet of paper," and her reasoning was mostly for convenience and practicality because "there's a lot of unnecessary clicking and opening of things, you could save effort by having in-text and then summative end comments at the end." Similarly, Alice explained that the end comment, which she called "comprehensive note," should appear on the student text. However, she purposefully constructed her note at beginning of the document, before the student text, rather than at the end. Alice did this because I see that [comprehensive note] as saying, one I want to preview what you should expect to see [in the marginal comments] because I want to frame the way you're 
going to read my comments, sometimes I over comment so I know it can be overwhelming... some people just think they did a bad job because there are lots of comments in the margin

Alice's placement of the comprehensive comment at the beginning of the document seeks to both frame her in-text commentary and reduce student anxiety about receiving comments on his/her text. Yet, of the five tutors and two instructors who participated in this study, no one other than Alice constructed the comprehensive note/end note at the beginning of the student's document.

\section{All tutors associated in-text with a "readerly" response and end comment with a "teacherly" response}

One of the most striking findings was that all five of the tutors associated the intext commentary with a "readerly" response and the end comment with a more "teacherly" response. In addition, all of the tutors made comments about teaching and the ways they responded to their own students' texts as they answered questions about their roles as tutors. For example, Alice explained

I like the in-text better because the commenting style is how I'm reading your paper as a reader not necessarily an evaluator, I mean it is an evaluation, but like, but as I read I'm thinking: this is where I'm confused, this is what I'm noticing, and with in-text I can put that right in... More like I'm saying these are the things

I'm noticing, this is my response to your piece

Later during the interview, Alice referred to this practice as "reader response." Prior to this project, Alice had responded to student texts in the virtual writing center with primarily in-text comments, and she seemed to want to resist the role of the "evaluator" 
when writing from the position of the tutor. In contrast, Lindsey was responding to her clients in the virtual writing center with an end comment response only. However, after participating in this project, she admitted her preference for in-text commenting. Like Alice, Lindsey also felt a "reader" as she commented in the margins of student text instead of at the end. Lindsey explained, "When I do in-text, I feel like I can insert myself as a reader into that text...it's more like a reading mind...I think it's a different kind of interacting actually, trying to put myself as a reader and give them my actual metacommentary, but doing the end comment I feel a lot more teacherly." Lindsey also explained that one of the weaknesses of the end comment response for her was that she "felt more like a teacher, [and that's] not an actual rhetorical situation, I'm not acting as a reader, I'm acting as a teacher and giving them tools."

\section{Tutors as "readers" help level power dynamics}

Another reason Lindsey preferred the "readerly role" to the "teacherly role" was because she felt that the power dynamics were more equalized when she responded as a reader. Lindsey explained that she found it essential for the tutor to provide the student writer with directions for how to read her marginal comments, and that then you put yourself in as a reader which ameliorates some issues that come up with power-when you talk to student writers as a reader of text it helps level the playing field a little...having them see the instructor as a reader and having them think of you as an audience member gets them to think about audience more In this explanation Lindsey suggested that "leveling the playing field" was important for tutors to consider while working with student writers and also that in-text comments encouraged students to think about audience. Since oftentimes in the virtual sessions 
tutors have even less context for the student's original writing task, Lindsey's desire for the student to maintain his/her autonomy seems especially important. When Lindsey restated her preference for the in-text format near the end of our interview, she connected this preference directly to her resistance to an authoritative role, "I found that I prefer the in-text, I don't know if that's because I'm anxious about my identity as the assessor, so being the reader is a way for me to ameliorate some of that stress so I can just be a reader instead of an instructor."

\section{Tutors as "teachers" encourage students to locate writing issues and revise places in} their own writing

In contrast to Lindsey, Scott preferred the end comment format to the in-text format, yet his reasoning for this was because he felt like a better teacher when he responded with the end comment. Thus, even though Scott's preference for the end comment, and the end comment exclusively, conflicted with the majority of the other tutors' preference for in-text commenting, he too understood the end comment as a more "teacherly" kind of response. Scott explained "The end comment is better because if not they [the students] end up focusing only on the sentences I comment on so the more I keep my hands off the better of a teacher I am, I think." Scott seemed unable to perceive the in-text commenting as a format with other kinds of potential beyond fixing, even though he did acknowledge some of its advantages, including the way it "lends itself to modeling and immediate intervention, [and its] very direct, very connected feedback can be really useful. [There is a] chance they will learn the lesson better that way because they actually can't miss it." Of the tutors interviewed, Scott seemed to be most reflective and the most aware of his own tendencies as a responder to student text. He admitted to 
his "struggle" with in-text commenting because of his tendency to "start talking grammar or a sentence fix which I didn't want to be wasting my time on but I just felt like I needed to say something and once I comment on a sentence I get really antsy and I can't not fix that so it was a struggle to keep myself from doing that and I usually failed." As a tutorteacher, Scott explained that we should be teaching students not only how to "fix" their writing, but also to identify that which needs to be fixed:

I feel like being able to identify is just as important as being able to fix...but the problem is they couldn't even identify until you pointed out so we have to figure out ways to help them, identify, because you can't fix without identifying. They[students] should begin being able to do their own teaching, fixing, learning which I don't think we do well when we only teach the fixing.

Here, Scott suggests that tutors should seek to teach students to both identify and fix issues in their own writing. He also said that in most sessions, he wanted to focus on higher order concerns, and the he was unable to see those higher order concerns when he commented using the in-text format because he was distracted by the sentence-level errors. Scott's explanation of the tutors role as one who teaches students how to look at their own writing and the end comment's ability to encourage that kind of work seemed similar to Lindsey's articulation of the end comment's strengths. Lindsey acknowledged that the end comment format "gets the writer to do the work [and I use] mini examples, and then tell them I noticed this here, here, and other places... I can see that helping student agency too, you're giving them different tools...it encourages them to go use those tools on their writing." Thus, tutors Lindsey and Scott suggested that the end comment has potential beyond the "fixing" of a particular paper. 


\section{Discussion}

Similar to the major findings in Study 1, this study found that formatting significantly affected the content and style of tutor commenting. In-text comments were shorter, more frequent, consisted of primarily sentence-level referents, and included more questions, rewriting, and rules. End comments were longer, fewer, consisted primarily of full-text referents, and included slightly more praise comments, although there were still very few. However, unlike the findings from Study 1, this study found that the in-text format included more comments that were observations when compared to observatory comments in the end comment.

Yet, there was one striking exception to this commonality: praise was extremely sparse in the virtual writing center responses especially when considered alongside the instructor responses. Furthermore, all five of the tutors who participated in this study were also first year composition instructors at the time of the study. Thus, the dual role of the instructor-tutor seemed to have an overall powerful influence, since the coded responses yielded very the same major findings. However, in terms of praise, there was a significant difference between instructor and tutor response

In addition to what this study reveals about the lack of praise in virtual writing center responses, this study also revealed that tutors felt a strong need to include a kind of hybrid response to student writing, even though they did prefer to favor one format over the other. As mentioned in the methods section of this study, tutors were resistant and unwilling to fully commit to solely one commenting style. Through interviewing them, I found that overall, tutors wanted to include short summative notes for students to read before accessing the in-text responses. These notes were often present in addition to the 
end note comment, and found either attached to student document before the student's text began or in the body of an email sent to the student with the virtual response attached as a word document.

This process of explaining to students how they should read their responses from tutors might be related to some tutors' desire to define their role as either "reader" and/or "instructor." Tutors seemed to feel a difference in terms of perceived authority depending on whether they were writing in-text comments or end comments. Only one of the five tutors admitted to being unable to stop himself from rewriting student text when constructing in-text comments; the others perceived the in-text format to be less directive and evaluative, and instead more readerly.

Despite their insistence on their role as readers not evaluators, these tutors also admitted to the strong influence their teaching experience had on the way they respond to student writing in the virtual writing center. One particularly important question that came out of this study is: should our role be to locate student "error" and the students' role to then figure out how to "fix" those "errors? Or, should our role be to teach students how to both locate and "fix errors" in their writing themselves? A further question is: how does or should the teaching of writing be similar or different in the context of the writing center compared to that of the classroom?

Of course there are limitations to this study that open up questions for future research, the most significant of which is the size of the study and context in which it took place. Additionally, coding and analyzing additional responses written by each tutor would provide a stronger sample for studying trends across tutors and individually. In addition, this study would have benefited from responses from students who use the 
virtual writing center and who would have been willing to submit multiple papers so that they could have received comments in both of the formats. More research is needed on the ways students read and understand virtual writing center responses, and on the ways in which graduate students and non-native speakers of English use and understand their responses in each of the formats. 


\section{CONCLUSION}

This thesis examined through the coding of teacher and tutor responses, student surveys, and interviews with instructors, tutors, and students how end comment and intext commenting formats affected the content and perceptions of instructor feedback. The responses were constructed by two first year composition instructors and five virtual writing center tutors who were also teaching composition at the time of their participation in this project.

These studies suggest that commenting format significantly impacted the comments provided by instructors and tutors. More specifically, in-text commenting in both the composition classroom and the virtual writing center consists of more frequent but shorter comments, more questions and explanations, and also more instructor/tutor rewriting of student text. These studies also indicate an overall preference for in-text commenting shared by students, instructors, and tutors. Yet, some students admitted that they revised more drastically in response to end comments and some of the instructor/tutors felt that the end comment was a more appropriate way for them to respond to student text because they felt that the format encouraged students to do more revising work. Thus despite instructors, tutors and students' preference for the in-text format, the end comment might be better in terms of more radical student revisions. This begs the questions: What are our goals for revision? Whose role is it to locate student writing issues, the teacher/tutor or the students'? Should we be teaching students to not just fix but also identify their own writing errors? 
Most strikingly, the findings from Study 1 suggest that praise might actually be a useful tool for revision, not just for confidence and easing students into comments. These findings were consistent Bardine's (2009) finding about high school students, yet the students in the current study admitted to using the places in their texts that received praise to assess other areas in their writing that were either strong or in need of revision. In addition, the instructors in this study seemed to follow some degree of Smith's (2007) "judging genre" which resulted in multiple end comments containing similar kinds of generic praise. Yet when instructors provided explanations for their praise, students were able to use those comments as tools for revision. Alternatively, tutors in the virtual writing center hardly praised student writing. While this finding is unfortunate due to the potential usefulness of praise in student revision, it is also not surprising since tutors generally focus their comments on improving student texts. However, the results from Study 1 suggest that tutors should spend at least some time providing thoughtful, explanatory praise.

In addition to consciously constructing explanatory praise, the findings from these studies suggest that both instructors and tutors should be aware of the different levels of directiveness and tones various commenting formats suggest. After participating in this study, instructors and tutors considered in-text formats to be more "readerly" compared to end comments which were considered to be more "teacherly." Although these findings do not attempt to determine which persona is more effective or appropriate, they do suggest that experimentation with and reflection on the ways in which comments and roles change according to different commenting formats was a useful practice for 
instructors and tutors. Furthermore, this kind of practice and reflection might (and in the case of these studies did) change the ways some tutors responded to student writing because they became more aware of the choices they have in constructing comments in either format. This kind of activity could be particularly valuable in instructor and virtual writing center tutor training.

Findings from these studies also suggest that some kind of introductory comprehensive note that explains to students how they should read instructor/tutor comments (especially in-text comments) could increase student understanding of instructor commentary. Instructors/tutors should make their own prioritizing explicit because not all students follow end comments in a particular way and students will find their own ways to prioritize comments, which may or may not be consistent with the instructor/tutors' intentions. Thus, it might be useful for instructors/tutors to tell students how to read, understand the function of, and prioritize their comments.

One obvious drawback of this study is the artificiality of asking instructors and tutors to comment using either in-text or end comment format. Nearly all of the instructors and tutors interviewed preferred some kind of hybrid format, though they still usually favored and/or constructed the majority of their comments using one format or the other. However, the purpose of this study was to bring to light the ways in which these two different formats lend themselves to different kinds of comments. This change in content was especially clear in terms of explanations and praise. If we understand the ways in which format affects the content of our comments, then perhaps we can make more conscious decisions about the ways we construct our feedback on student texts. 
This study does not suggest that either in-text or end comment format should be practiced exclusively or consistently by all instructors/tutors with all student writers. This study also does not suggest that either format results in a higher quality of student writing or revision. Instead, this study shows that commenting format does result in different kinds of comments, instructor/tutor personas, and student perceptions of instructor comments. Future research is needed to determine the ways in which these formats do affect student revision and the ways in which these formats are perceived by students writing at different levels and in different genres. 


\section{REFERENCES}

Bardine, B. (1999). Students' perceptions of written teacher comments: What do they say about how we respond to them? The High School Journal, 82(4), 239-247.

Beach, R., Anson, C., Breuch, L. K., \& Swiss, T. (2002). Teaching writing using blogs, wikis, and other digital tools. Norwood, MA: Christopher-Gordon Publishers, Inc. Web.

Bean, J. (2011). Engaging ideas: the professor's guide to integrating writing, critical thinking, and active learning in the classroom. San Francisco: Jossey-Bass.

Brooks, J. (2008). Minimalist tutoring: Making the students do all the work. In Murphy, C. \& Sherwood, S. (Eds.) ( $3^{\text {rd }}$ ed.), The St. Martin's Sourcebookfor Writing Tutors (pp. 168-172). Boston: Bedford/St. Martin’s.

Cho, K., Schunn, C. \& Charney, D. (2006). Commenting on writing: Typology and perceived helpfulness of comments from novice peer reviewers and subject matter experts. Written Communication, 23(3), 260-294.

Connors, R. \& Lunsford, A. (1988). Frequency of formal error in current college writing, or Ma and Pa Kettle do research. College Composition and Communication, 39(4), 395-409.

Connors, R \& Lunsford, A. (1993)Teachers' rhetorical comments on student papers. College Composition and Communication, 44( 2), 200-223. 
Daiker, D. (1989). Learning to praise. In Anson, C.M. (Ed.), Writing and response: Theory, practice and research (pp.103-113). Urbana, IL: NCTE.

Dohrer, G. (1991). Do teachers' comments on students' papers help? College Teaching, $39(2), 48-54$.

Dweck, C. (2007) The perils and promises of praise. Educational Leadership, 65(2), 3449.

Geller, A., Eodice, M., Condon, F., Carroll, M., Boquet, E. (2007). The Everyday Writing Center: A Community of Practice. Logan, UT: Utah State U P.

Haswell, R. (1983). Minimal marking. College Composition and Communication, 45(6), $600-604$.

Hayes, M. F. \& Daiker, D. A. (1984). Using protocol analysis in evaluating responses to student writing. Freshman English News, 13, 1-4.

Heller, D. (1989). Silencing the soundtrack: An alternative to marginal comments. College Composition and Communication, 40(2), 210-215.

Hewett, B. (2006). Synchronous online conference-based instruction: A study of whiteboard interactions and student writing. Computers and Composition, 23, 431.

Hewett, Beth L. The Online Writing Conference: A Guide for Teachers and Tutors. Portsmouth, NH: Boynton/Cook, 2010. Print.

Lunsford, A. \& Lunsford, K. (2008). 'Mistakes are a fact of life': A national comparative study. College Composition and Communication, 59(4), 781-806. 
McGarth, A., Taylor, A. \& Pychyl, T. (2011). Writing helpful feedback: The influence of feedback type on students' perceptions and writing performance. The Canadian Journal for the Scholarship of Teaching and Learning, 2(2), 1-13.

Neaderhiser, S. \& Wolfe, J. 2009. Between technological endorsement and resistance: the state of online writing centers. The Writing Center Journal, 29(1), 49-77.

Shamoon, L. \& Burns, D.(2008). A critique of pure tutoring. In Murphy, C. \& Sherwood, S. (Eds.) ( $3^{\text {rd }}$ ed.), The St. Martin's Sourcebook for Writing Tutors (pp. 173-188). Boston: Bedford/St. Martin's.

Smith, S. (1997). The genre of the end comment: Convention in teacher responses to student writing. National Council of Teachers of English, 48(2), 249-268.

Sommers, N. (1982). Responding to student writing. College Composition and Communication, 33(2), 148-156.

Straub, R. (1996). The concept of control in teacher responses: Defining the varieties of "directive" and "facilitative" commentary. National Council of Teachers of English, 47(2), 223-251.

Straub, R. (1997). Students' reactions to teacher comments: An exploratory study. Research in the Teaching of English, 31(1), 91-119.

Walker, M. (2009). An investigation into written comments on assignments: Do students find them usable? Assessment and Evaluation in Higher Education, 34(1), 67-78. 
Wallace, D. \& Hayes, J. (1991). Redefining revision for freshmen. Teaching of English, 25(1), 54-66.

Wojahn, P.G., Neuwirth, C.M. \& Bullock, B. (1998). Effects of interfaces for annotation on communication in a collaborative task. $C H I, 98,18-23$.

Ziv, N.D. (1984). The effect of teacher comments on the writing of four college freshmen. In Beach, R. \& Bridwell, L.S. (Ed.), New Directions in Composition Research (pp. 362-380). New York: Guilford. 


\section{CURRICULUM VITAE}

\section{Rebecca L. Hallman}

University of Louisville

Department of English

rebecca.hallman@louisville.edu

$\underline{502.551 .1247}$

Education

M.A. in English, Rhet/Comp

University of Louisville

Transylvania University

Expected 2012

2009

\section{International Study Abroad Experience}

Brazilian Studies Exchange Program, Sao Paulo State University, Brazil 2010

International Shakespeare Summer School, Cambridge University, England 2008

Service Learning in the Philippines, Mactan Island, Philippines

2008

\section{Academic Honors and Awards}

Graduate Teaching Assistantship, University of Louisville, 2010-present

Transylvania University, Full-tuition Transylvania Scholarship, 2007-2009

English-Speaking Union, Summer Abroad Scholarship, 2007-2008

\section{Scholarly Presentations}

"It's not what you say but how you form it: Investigating Commenting Formats and Content in Virtual Writing Center Responses." Southwestern Writing Center Association Conference. Richmond, KY. February 2012.

"Speaking Silence in the Writing Center." Kentucky Philological Association. Frankfort, KY. March 2011.

\section{Grants}

Graduate School Committee (Travel Funding), 2012

UofL Writing Center (Travel and Registration Funding), 2011 
UofL Professional Development (Travel and Registration Funding), 2011

Transylvania Kenan Grant (Research Funding), 2008

\section{Teaching Experience}

\section{University of Louisville, 2010-present}

English 101: Introduction to College Writing English 102: Intermediate College Writing Writing Center Consultant: Health Sciences Campus and Central Writing Center ESL Instructor: Intermediate-level English Conversation (summer internship at America English School, Rio Preto, Brazil)

\section{Transylvania University, 2006-2009}

WRC 2002: Writing Center Practicum (Teaching Assistant)

Writing Center Consultant (Basic Writing and ESL specialist)

\section{Memberships}

International Writing Center Association, 2011-present

National Council for Teachers of English, 2011-present

Modern Languages Association, 2011-present

University of Louisville English Graduate Organization, 2010-present

Service

Volunteer. UofL English Graduate Organization Book Fair, 2010

Discussion Leader. First Engagements Book Project. Transylvania University, 2007-2009

Publicity Officer for Transylvania Literary Magazine. Transylvania University, 2009

Kentucky Delegate. Powershift 2009: National Youth Summit, Washington, D.C. 2009

Cultural Affairs Educator. Transylvania University, Mactan Island, Philippines, 2008

\section{Professional Development}

Workshop Participant. Obtaining External Research Funds, CCCCs, St. Louis, 2012

Participant. 2012 Envisioning Teaching and Learning in the Digital Age, UofL, 2012

Research Assistant for Dr. Mary Rosner. University of Louisville, 2011-present Faculty Representative. UofL English Graduate Organization. 2011-present 
Participant, Graduate Teaching Academy. University of Louisville, 2011-present Student Participant, Watson Symposium. University of Louisville, 2011 Participant, Writing Center Retreat. Eastern Kentucky University, 2011 Attendant, Watson Conference. University of Louisville, 2010 